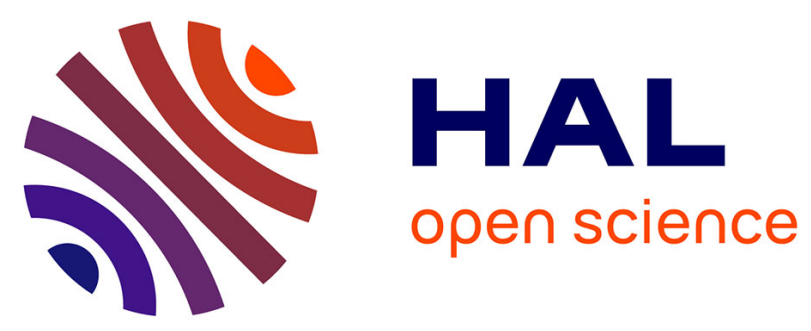

\title{
Production rates of bacterial tetraether lipids and fatty acids in peatland under varying oxygen concentrations
}

Arnaud Huguet, Travis B Meador, Fatima Laggoun-Défarge, Martin Könneke, Weichao Wu, Sylvie Derenne, Kai-Uwe Hinrichs

\section{- To cite this version:}

Arnaud Huguet, Travis B Meador, Fatima Laggoun-Défarge, Martin Könneke, Weichao Wu, et al.. Production rates of bacterial tetraether lipids and fatty acids in peatland under varying oxygen concentrations. Geochimica et Cosmochimica Acta, 2017, 203, pp.103-116. 10.1016/j.gca.2017.01.012 . insu-01438807

\section{HAL Id: insu-01438807 https://hal-insu.archives-ouvertes.fr/insu-01438807}

Submitted on 18 Jan 2017

HAL is a multi-disciplinary open access archive for the deposit and dissemination of scientific research documents, whether they are published or not. The documents may come from teaching and research institutions in France or abroad, or from public or private research centers.
L'archive ouverte pluridisciplinaire HAL, est destinée au dépôt et à la diffusion de documents scientifiques de niveau recherche, publiés ou non, émanant des établissements d'enseignement et de recherche français ou étrangers, des laboratoires publics ou privés.

\section{(ㅇ)(1) $\$$}

Distributed under a Creative Commons Attribution - NonCommercial - NoDerivatives 44.0 


\section{Accepted Manuscript}

Production rates of bacterial tetraether lipids and fatty acids in peatland under varying oxygen concentrations

Arnaud Huguet, Travis B. Meador, Fatima Laggoun-Défarge, Martin Könneke, Weichao Wu, Sylvie Derenne, Kai-Uwe Hinrichs

PII:

S0016-7037(17)30016-9

DOI: http://dx.doi.org/10.1016/j.gca.2017.01.012

Reference: GCA 10106

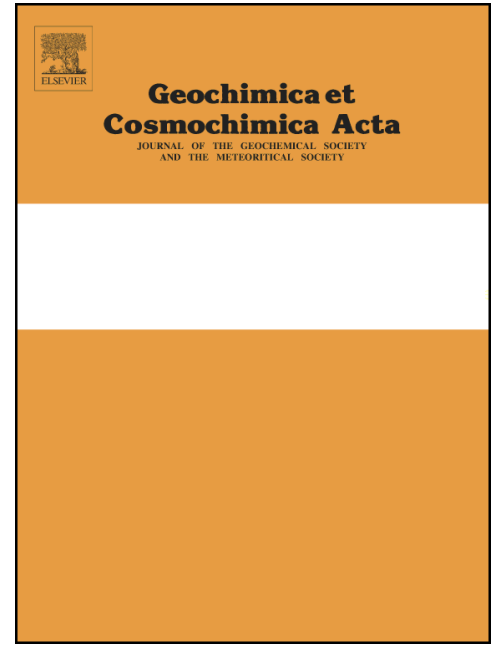

To appear in:

Geochimica et Cosmochimica Acta

Received Date:

23 August 2016

Revised Date:

3 January 2017

Accepted Date:

8 January 2017

Please cite this article as: Huguet, A., Meador, T.B., Laggoun-Défarge, F., Könneke, M., Wu, W., Derenne, S., Hinrichs, K-U., Production rates of bacterial tetraether lipids and fatty acids in peatland under varying oxygen concentrations, Geochimica et Cosmochimica Acta (2017), doi: http://dx.doi.org/10.1016/j.gca.2017.01.012

This is a PDF file of an unedited manuscript that has been accepted for publication. As a service to our customers we are providing this early version of the manuscript. The manuscript will undergo copyediting, typesetting, and review of the resulting proof before it is published in its final form. Please note that during the production process errors may be discovered which could affect the content, and all legal disclaimers that apply to the journal pertain. 


\title{
Production rates of bacterial tetraether lipids and fatty acids in peatland under varying oxygen concentrations
}

Arnaud Huguet ${ }^{1, \S_{*}}$, Travis B. Meador ${ }^{2} \S^{*}$, Fatima Laggoun-Défarge ${ }^{3}$, Martin Könneke ${ }^{2}$, Weichao $\mathrm{Wu}^{2}$, Sylvie Derenne ${ }^{1}$, Kai-Uwe Hinrichs ${ }^{2}$

${ }^{1}$ Sorbonne Universités, UPMC, Univ Paris 06, CNRS, EPHE, UMR 7619 METIS, 4, place Jussieu, 75252 Paris cedex 05, France

${ }^{2}$ MARUM Center for Marine Environmental Sciences and Dept. of Geosciences, University of Bremen, 28359 Bremen, Germany

${ }^{3}$ ISTO, CNRS/Université d'Orléans /BRGM UMR 7327, Orléans F-45071, France

$\S$ these authors contributed equally to this manuscript

(*corresponding authors: arnaud.huguet@upmc.fr, travis.meador@uni-bremen.de)

\begin{abstract}
Interpretations of the abundance and distribution of branched glycerol dialkyl glycerol tetraether (brGDGT) lipids have been increasingly applied to infer changes in paleoenvironment and to estimate terrigenous organic matter inputs into estuarine and marine sediments. However, only preliminary information is known regarding the ecology and physiology of the source organisms of these biomarkers. We assessed the production rates of brGDGTs under different redox conditions in peat, where these lipids are found in high concentrations, particularly at greater depths below the fluctuating water table. The incorporation of hydrogen relative to carbon into lipids observed in our dual stable isotope probing assay indicates that brGDGTs were produced by heterotrophic bacteria. Unexpectedly, incubations with stable isotope tracers of the surface horizon $(5-20 \mathrm{~cm})$ initiated under oxic conditions before turning suboxic and eventually anoxic exhibited up to one order of magnitude higher rates of brGDGT production $\left(16-87 \mathrm{ng} \mathrm{cm}^{-3} \mathrm{y}^{-1}\right)$ relative to the
\end{abstract}


deeper, anoxic zone (20- $35 \mathrm{~cm}$; ca. $\left.7 \mathrm{ng} \mathrm{cm}^{-3} \mathrm{y}^{-1}\right)$, and anoxic incubations of the surface horizon $\left(<3 \mathrm{ng} \mathrm{cm}^{-3} \mathrm{y}^{-1}\right)$. Turnover times of brGDGTs in the surface horizon ranged between 8 and 41 years in the incubations initiated under oxic conditions, in contrast to 123 to 742 years in anoxic incubations. As brGDGTs were actively produced during both anoxic incubations and those exposed to oxygen, we conclude that their source organisms are likely facultative aerobic heterotrophs that are particularly active in the peat acrotelm. Production rates of bacterial fatty acids (ca. $2 \mu \mathrm{g} \mathrm{cm} \mathrm{y}^{-3} \mathrm{y}^{-1}$ ) were roughly two orders of magnitude higher than those of brGDGTs, suggesting that brGDGT producers are a minor constituent of the microbial community or that brGDGTs are a small component of the microbial cell membrane in comparison to fatty acids, despite the typically high brGDGT concentrations observed in peat. Multivariate analysis identified two branched fatty acids that shared a similar production pattern as brGDGTs among the experimental treatments and may be associated with brGDGT biosynthesis. 


\section{INTRODUCTION}

The cell membranes of bacteria are primarily composed of acylglycerol fatty acid lipids (Kaneda, 1991), i.e. straight or branched alkyl chains linked by ester bonds to a glycerol backbone, while archaeal membranes are generally composed of isoprenoid alkyl chains linked by ether bonds to a glycerol backbone, forming glycerol dialkyl diethers and glycerol dialkyl glycerol tetraethers (GDGTs; e.g. De Rosa and Gambacorta, 1988; Schouten et al., 2013). Another class of GDGT lipids containing branched instead of isoprenoid alkyl chains was discovered in peat deposits (Sinninghe Damsté et al., 2000). The structure and stereochemistry of these branched GDGTs (brGDGTs) led to the suggestion that they are produced by still unknown bacteria (Weijers et al., 2006), although circumstantial evidence suggests that some of the producers might belong to the phylum Acidobacteria (Weijers et al., 2009; Sinninghe Damsté et al., 2011, 2014). BrGDGTs were shown to be widely distributed in terrestrial (e.g. Weijers et al., 2007; Huguet et al., 2013a) and aquatic (e.g. Tierney et al., 2010; Zell et al., 2014) environments. They are the subject of growing interest, as their degree of methylation, expressed by the MBT index, was shown to correlate with air temperature and to a lesser extent with soil $\mathrm{pH}$, whereas the relative abundance of cyclopentyl rings, expressed by the CBT index, was observed to depend on soil pH (Weijers et al., 2007). The MBT/CBT proxy has been increasingly used to reconstruct past air temperatures, e.g. in loess (Peterse et al., 2014), peat (Weijers et al., 2011; Zheng et al., 2015) or lakes (Colcord et al., 2015; Loomis et al., 2015).

Even though many studies have focused on the use of brGDGTs as temperature proxies (Schouten et al., 2013 and references therein), to date little information is known regarding the microbial sources and the rates at which these lipids are produced. BrGDGT-producing bacteria were suggested to colonize anoxic habitats, as brGDGTs were found to be much 
more abundant in the deeper and permanently anoxic zone (i.e. catotelm) of Sphagnumdominated peatlands than in the surficial oxic layer (i.e. acrotelm) (Weijers et al., 2006; Huguet et al., 2010; Peterse et al., 2011). De Jonge et al. (2014) suggested an additional source of brGDGTs in the oxic, riverine water column to explain the distinct patterns of brGDGT methylation and cyclization in suspended particles compared to soils. BrGDGT source microorganisms were also suggested to be heterotrophs, based on (i) the stable carbon isotopic relationships of brGDGT-derived alkyl moieties and bulk organic carbon in contrasting soils (Oppermann et al., 2010; Weijers et al., 2010), (ii) the similar carbon isotopic profiles of brGDGT-derived alkyl skeletons with other microbial biomarkers (archaeal-derived biphytanes and bacterial hopanes) in a peat deposit (Pancost and Sinninghe Damsté, 2003), (iii) their close association with the root surface (Ayari et al., 2013; Huguet et al., 2013b), and (iv) the higher abundance of brGDGTs in calcified roots than in surrounding terrestrial sediments (Huguet et al., 2012, 2013b). BrGDGTs are known to be extremely abundant in peat bogs, suggesting that these provide a favorable habitat for their source microorganisms. Based on changes in lipid distributions in both laboratory and field experiments, Huguet et al. $(2013,2014)$ suggested that brGDGT source microorganisms in peat were highly active, to the effect that adjustment of their membrane lipids in response to changes in soil temperature resulted in detectable changes of lipid composition already after one year. Quantification of the microbial community members based on 16S rRNA in a peat bog revealed that members of the Acidobacteria, which are versatile heterotrophs abundant in peat and acidic soils (e.g. Pankratov et al., 2008; Jones et al., 2009), account for the majority of the bacteria, and thus were suggested to encompass brGDGT source organisms (Weijers et al., 2009). A subsequent lipid survey detected tetraether lipids as a minor lipid constituent in 3 of 17 members of the phylum Acidobacteria (Sinninghe Damsté 
et al, 2011). Additional work is still required to investigate the metabolism of brGDGT source microorganisms and to assess the production rate of brGDGTs in Sphagnum-dominated peatlands and other environments, in order to further substantiate the paleoenvironmental interpretations derived from these lipids.

The activity, growth, and turnover times of microbial communities in environmental samples can be assessed using stable isotope probing (SIP), which traces the incorporation of labeled substrates into molecular biomarkers (such as lipids) produced by living organisms, with the advantage that pure cultures are not required (e.g. Boschker et al., 1998; Kopf et al., 2016). Recently, a dual SIP approach, with concomitant additions of deuterated water $\left(D_{2} \mathrm{O}\right)$ and ${ }^{13} \mathrm{C}$-labeled dissolved inorganic carbon $\left({ }^{13} \mathrm{C}_{\mathrm{DIC}}\right)$, was applied to marine sediments (e.g. Kellermann et al., 2012; Wegener et al., 2012), enabling direct quantification of lipid synthesis rates and distinction of heterotrophic and autotrophic microbial communities in natural samples.

To determine the production rates of brGDGTs and further investigate the metabolism of brGDGT-producing bacteria, peat samples from a Sphagnum-dominated peatland (Jura Mountains, France; Huguet et al., 2013) were subjected to SIP experiments amended with both $\mathrm{D}_{2} \mathrm{O}$ and $\mathrm{NaH}^{13} \mathrm{CO}_{3}$. Peat samples were collected from the surficial acrotelm and deeper catotelm, and were incubated under both anoxic and oxic conditions for the acrotelm samples and only anoxic conditions for the catotelm. This approach enabled us to assess the preferential growth conditions of brGDGT source microorganisms and to quantify and compare for the first time the production rate of brGDGTs in relation to the bulk microbial community in peat.

\section{MATERIALS AND METHODS}




\subsection{Sample collection}

Samples were collected in April 2014 from the Frasne peatland (Jura Mountains, France; $\left.46^{\circ} 49^{\prime} \mathrm{N}, 6^{\circ} 10^{\prime} \mathrm{E}\right)$, located at $840 \mathrm{~m}$ altitude. This undisturbed Sphagnum-dominated mire has been classified as a Region Natural Reserve for more than 20 years. Annual precipitation is between 1300 and $1500 \mathrm{~mm}$ and mean annual air temperature measured over the 20082010 period was $6.8^{\circ} \mathrm{C}$, with cold winters (mean $-1.5^{\circ} \mathrm{C}$ ) and mild summers (mean $16.0^{\circ} \mathrm{C}$; Delarue et al., 2011; Huguet et al., 2013a). Peat cores were collected from two contrasting sites: (i) a transitional Sphagnum-dominated poor fen area and (ii) an open bog area with mixed vegetation (Sphagnum spp., Eriophorum and other vascular plants, e.g. Andromeda polifolia). The former site is hereafter called the "fen site" and the latter the "bog site".

Two peat cores (ca. $40 \mathrm{~cm}$ length and $30 \mathrm{~cm}$ diameter) were collected from each site. The green section of each core $(0-5 \mathrm{~cm}$; 0 being defined as the top of the Sphagnum capitulum) was discarded during sampling. The cores were cut into 3 sections directly in the field (sampling depth): $5-15 \mathrm{~cm}, 15-20 \mathrm{~cm}$ and $20-30 \mathrm{~cm}$ for the fen site; $10-20 \mathrm{~cm}, 20-25 \mathrm{~cm}$ and $25-35 \mathrm{~cm}$ for the bog site. The samples were kept at $4{ }^{\circ} \mathrm{C}$ for a few days before starting the incubation experiments.

\subsection{Preparation of incubation experiments}

For each site, samples from the surficial oxic layer $(5-15 \mathrm{~cm}$ for the fen site and $10-20 \mathrm{~cm}$ for the bog site) and deeper anoxic layer $(20-30 \mathrm{~cm}$ for the fen site and $25-35 \mathrm{~cm}$ for the bog site) were incubated. Incubations of the deeper anoxic section (so-called catotelm) were initiated under anoxic conditions. To mimic the fluctuating water table and thus the transition from oxic to anoxic conditions, incubations of the surficial section (so-called 
acrotelm) were initiated under both oxic and anoxic conditions. At the time of sampling, the water table level was $11.5 \mathrm{~cm}$ at the fen site and $14 \mathrm{~cm}$ at the bog site. Therefore, the upper layers (5-15 cm for the fen site and $10-20 \mathrm{~cm}$ for the bog site) are not purely acrotelm samples as they partly cover the mesotelm and beginning of the catotelm section, but will be defined as such in the rest of the manuscript for simplification.

The acrotelm samples were incubated for 2 months under either initially oxic or anoxic conditions, with a time point also harvested after 1 month for the initially oxic incubations only. The catotelm samples were incubated for 1 month under anoxic conditions only. Time zero $\left(t_{0}\right)$ samples were taken directly from the peat core after collection and frozen at $-20^{\circ} \mathrm{C}$ until extracted. Note that subsequent time point samples for each treatment refer to samples that were incubated independently in different bottles. We compare several treatment variables (bog vs. fen; oxic vs. anoxic; acrotelm vs. catotelm), which could not be replicated due to limitations of peat material and the processing time for each incubation. Therefore, we are not able to assess the statistical significance of differences in lipid production between incubations but instead refer to the fold-differences observed between the experiments.

In order to avoid contamination, all samples were prepared with microbiological techniques at aseptic conditions including the sterilization of all glassware, stoppers, and utensils used to prepare the incubation experiments by autoclaving $\left(123^{\circ} \mathrm{C}\right.$ for $\left.20 \mathrm{~min}\right)$. Samples for anoxic incubation were prepared inside an anoxic chamber filled with $\mathrm{N}_{2} / \mathrm{H}_{2}$ $(95 / 5 \%)$ and the headspace was subsequently purged with $\mathrm{N}_{2}$. Initially oxic incubations were prepared on a surface sterilized with ethanol, then sealed to prevent escape of labeled ${ }^{13} \mathrm{CO}_{2}$, which would have compromised estimates of autotrophic production. Given the initial amount of $1.25 \mathrm{mmol} \mathrm{O}_{2}$ in the headspace and typical peat respiration rates of $1.75 \mu \mathrm{mol} \mathrm{m}$ 
$s^{-1}$ in Frasne (D'Angelo et al., 2016), the incubations were expected to remain aerobic for at least 22 days, then transition to suboxic and eventually anoxic conditions (Table S1).

All samples were incubated at $12^{\circ} \mathrm{C}$, consistent with the mean air temperature at the sampling site in spring and summer (Huguet et al., 2013a), i.e. when the peatland is not snow-covered and when the microbial activity is expected to be maximal (e.g. Blume et al., 2002). Approximately $100 \mathrm{~g}$ of peat was weighed into $250 \mathrm{~mL}$ culture flasks and amended with a sterilized artificial media $(25 \mathrm{~mL})$ containing sodium chloride $\left(0.5 \mathrm{~g} \mathrm{~L}^{-1}\right)$, magnesium sulfate heptahydrate $\left(0.3 \mathrm{~g} \mathrm{~L}^{-1}\right)$, calcium chloride $\left(0.2 \mathrm{~g} \mathrm{~L}^{-1}\right)$, potassium chloride $\left(0.2 \mathrm{~g} \mathrm{~L}^{-1}\right)$, sodium bicarbonate $\left(10 \mathrm{mmol} \mathrm{L}^{-1}\right)$, and isotopically labeled sodium bicarbonate and deuterated water $\left(D_{2} O\right)$. The resulting ${ }^{13} \mathrm{C}$ fraction was ca. $6 \%$ of dissolved inorganic carbon and $\mathrm{H}$ isotopic enrichment was ca. $5 \%$ deuterium in total water. Poisoned incubations of bog and fen samples from the acrotelm were amended with zinc chloride $\left(\mathrm{ZnCl}_{2}\right)$ to a final concentration of ca. $0.02 \mathrm{~g} \mathrm{~mL}^{-1}$ and incubated for two months, initially under oxic conditions. For these killed control experiments, poisoning with $2.5 \mathrm{~mL}$ of $\mathrm{ZnCl}_{2}\left(1 \mathrm{~g} \mathrm{~mL}^{-1}\right)$ was preferred to autoclaving, as heating by the latter technique can potentially alter the matrix of natural organic matter in peat and/or introduce abiotic D into lipids (e.g., Sessions et al., 2004; Reeves et al., 2012).

\subsection{Sample preparation}

After the incubation period (one or two months), culture flasks were placed directly into a $-80^{\circ} \mathrm{C}$ freezer for at least $18 \mathrm{~h}$ and subsequently lyophilized for up to two weeks. Samples were then extracted using a modified Bligh and Dyer method (Sturt et al., 2004) to generate a total lipid extract (TLE). Aliquots of the TLE (10\%) were prepared for lipid quantification via tandem high performance liquid chromatography mass spectrometry (HPLC-MS/MS), as 
described below (cf. section 2.4). $80 \%$ of the TLE was subjected to a series of preparative HPLC protocols. Firstly, core lipids (CLs; without head groups) and intact polar lipids (IPLs; with head groups) were separated using an Inertsil Diol column $(5 \mu \mathrm{m}, 10 \times 150 \mathrm{~mm})$ as described by Meador et al. (2014). The two fractions were evaporated under a stream of $\mathrm{N}_{2}$ gas.

The IPLs were further purified using an Agilent Eclipse XDB-C18 column $(5 \mu \mathrm{m}, 9.4 \times 250$ $\mathrm{mm}$ ) and a binary elution gradient consisting of methanol (solvent A) and isopropanol (solvent B). The gradient ramped from an initial setting of $20 \% \mathrm{~B}$ to $40 \% \mathrm{~B}$ in $5 \mathrm{~min}$, followed by a gradient to $65 \%$ B over $35 \mathrm{~min}$ and then increased to $100 \%$ B over $10 \mathrm{~min}$, held for 10 min. The flow rate was $2.2 \mathrm{~mL} \mathrm{~min}^{-1}$ and the column was re-equilibrated with $20 \% \mathrm{~B}$ for 20 min before the next injection. The 26 to 34 min fraction containing glycosylated brGDGTs was collected and evaporated under $\mathrm{N}_{2}$.

The CL fraction was further purified using a PerfectSil $100 \mathrm{CN}-3$ column $(5 \mu \mathrm{m}, 10 \times 250$ $\mathrm{mm}$ ) and a binary elution gradient beginning with 100\% hexane/isopropanol 99:1 (v/v; solvent A) and ramping to $10 \%$ hexane/isopropanol 90:10 (v/v; solvent B) in $15 \mathrm{~min}$, followed by a gradient to $60 \% \mathrm{~B}$ at $30 \mathrm{~min}$ and then increased to $100 \% \mathrm{~B}$ at $30.1 \mathrm{~min}$, holding for 9.9 min. The flow rate was $3 \mathrm{~mL} \mathrm{~min}-1$ and the column was re-equilibrated with $100 \% \mathrm{~A}$ for 8 min before the next injection. The 17 to 28.5 min fraction containing the brGDGT-CLs was collected and evaporated under $\mathrm{N}_{2}$ gas. This purification step was essential to remove impurities that otherwise increased the analytical background and obstructed stable isotopic determination of brGDGT derivatives.

\subsection{Quantification of bacterial lipids}


The quantification of brGDGT-CLs was performed with a Dionex Ultimate 3000 ultra-high pressure liquid chromatography (UHPLC) system coupled to a Bruker maXis ultra-high resolution quadrupole time-of-flight (QTOF) mass spectrometer via an APCI II source and using two Acquity BEH HILIC amide columns in tandem $(2.1 \times 150 \mathrm{~mm}, 1.7 \mu \mathrm{m}$, Waters, Germany), as described by Becker et al. (2013; Table S2). BrGDGT-IPLs were quantified using the aforementioned QTOF instrument, following the methodology described by Zhu et al. (2013; Table S2). Lipids were scanned from $\mathrm{m} / \mathrm{z} 100$ to 2000 at a rate of $1 \mathrm{~Hz}$, with automated data-dependent fragmentation of the three most abundant ions selected for collision-induced dissociation. Semi-quantification of the brGDGTs was achieved using a $\mathrm{C}_{46}$ tetraether internal standard (Huguet et al., 2006), which was added to each sample before injection. Because no standards for brGDGT-CLs and -IPLs are available, we determined the MS response factors for analogous tetraether standards (acyclic isoprenoidal GDGT and monoglycosidic isoprenoidal GDGT purified in our laboratory from Archaeoglobus fulgidis) relative to the $C_{46}$ internal standard ( 0.59 and $5 \times 10^{-3}$, respectively). In the following, we assume similar MS response for branched and isoprenoid GDGTs. The coefficient of variation (CV) for replicate injections was $7.9 \%$ for brGDGT-CLs. CV of $11 \%$ was assumed for brGDGTIPLs, based on replicate injections of a solution containing monoglycosidic archaeol and tetraether lipids purified from $A$. fulgidis.

For fatty acid quantification, bulk TLE aliquots (2-5\%) were dried and saponified in $2 \mathrm{~mL}$ of $1 \mathrm{M} \mathrm{KOH}$ at $80^{\circ} \mathrm{C}$ for 2 hours. The basic aqueous solution was extracted four times with $n$ hexane to remove neutral lipids. The remaining aqueous fraction was acidified to $\mathrm{pH} 2$ by adding ca. 8 drops of $6 \mathrm{M}$ hydrochloric acid and fatty acids were extracted four times with 1 $\mathrm{mL} n$-hexane, then dried under a stream of $\mathrm{N}_{2}$ gas. Fatty acid methyl esters (FAMEs) were prepared via derivatization with $25 \%$ boron trifluoride in methanol (Aldrich, Germany) at 
$70^{\circ} \mathrm{C}$ for 1 hour and were subsequently extracted with $n$-hexane as described above. FAMEs were injected onto a gas chromatograph (GC) interfaced with a flame ionization detector (FID) and were quantified relative to a squalene standard; the CV for individual fatty acid peaks ranged from 1.7 to $9.3 \%$. The identity of the FAME peaks was verified by expected masses and fragmentation patterns observed during GC/MS (Fig. S1). GC/MS and GC/FID analyses were performed on an Agilent 5973 inert MSD and on a Thermo Scientific Trace GC Ultra coupled to a FID, respectively. Both GCs were equipped with a Restek Rxi-5ms column (30 $\mathrm{m} \times 250 \mu \mathrm{m} \times 0.25 \mu \mathrm{m}$; Restek, Germany) and analyses were performed according to Lin et al. (2012).

\subsection{Ether cleavage and stable isotopic analyses}

Branched alkyl chain derivatives were released from purified fractions of brGDGT-IPLs and -CLs following the ether cleavage method described by Jahn et al. (2004), and were injected onto GC/MS and GC/FID (as above) to monitor recovery and verify purity of the eluting peak (Fig. S2). FAMEs were directly amenable to gas chromatography isotope ratio mass spectrometry (GC/IRMS) analysis. The ${ }^{13} \mathrm{C}$ and deuterium (D) isotopic composition of bulk FAMEs and brGDGT derivatives were measured via GC/IRMS as described by Kellermann et al. (2012) and are expressed in standard $\delta$ notation, as the deviation of the isotope ratio from reference standards: $\delta D=\left([D / H]_{\text {sample }} /[D / H]_{\text {ref }}-1\right) \times 1000$ (reference is VSMOW) and $\delta{ }^{13} \mathrm{C}=\left(\left[{ }^{13} \mathrm{C} /{ }^{12} \mathrm{C}\right]_{\text {sample }} /\left[{ }^{13} \mathrm{C} /{ }^{12} \mathrm{C}\right]_{\text {ref }}-1\right) \times 1000$ (reference is VPDB). Replicate analyses of nonlabeled brGDGTs derivatives from bog and fen acrotelm (i.e. $t_{0}$ samples) were within $10 \%$ for $\delta \mathrm{D}$ and $1.2 \%$ for $\delta^{13} \mathrm{C}$. Compared to the natural abundances of $\mathrm{D}$ (ca. 1 atom per $6240{ }^{1} \mathrm{H}$ atoms) and ${ }^{13} \mathrm{C}$ (ca. 1 atom per $90{ }^{12} \mathrm{C}$ atoms), the isotope ratios of labeled analytes are much higher, effectually lowering GC-IRMS detection limits and increasing measurement accuracy. 
The measurement uncertainty of highly D-labeled compounds was assessed via replicate injections of FAMEs obtained from other SIP incubations of marine sediments using $1 \% D_{2} \mathrm{O}$ (Table S6). D-labeled lipid biomarkers were also obtained from a cultured archaeon, Methanosarcina barkeri, grown on $\mathrm{H}_{2} / \mathrm{CO}_{2}$ or methanol after Penger et al. (2014) in the presence of 0.2 to $0.5 \% \mathrm{D}_{2} \mathrm{O}$. Replicate injections of D-labeled lipid biomarkers, including $\mathrm{C}_{16: 1}$ (labeling strength: $1,000 \% \circ<\delta \mathrm{D}<17,000 \%$ ) and $\mathrm{C}_{18: 1}$ fatty acids $(300 \% \circ<\delta \mathrm{D}<$ 4,000\%), archaeol $(3,000 \% \circ<\delta D<5,300 \%$, and saturated and unsaturated pentamethylicosane (PMI; 4,000\% $<\delta D<15,000 \%$ ) exhibited coefficients of variation ranging up to $7.5 \%$ (Table S6). This error of the $\delta \mathrm{D}$ measurement pertains to labeled fatty acids or brGDGT derivatives with values > 100\%; otherwise the error determined from replicate injections of $t_{0}$ samples applies (i.e., $\pm 10 \%$ ).

\subsection{Calculation of lipid production rates}

Because incubations of the natural peat samples were not amended with substrates to induce growth or otherwise enrich targeted members of the microbial community, we assume that the concentration of lipids in each incubated bottle remained constant during the incubation period (Text S1). The production rate of lipids ( $\operatorname{prod}_{\text {lipid }}$ ) was therefore calculated by multiplying lipid concentration ( conc $_{\text {lipid }}$ ), which was determined for each different incubation bottle, by the increase of the fraction of $\mathrm{D}$ in the lipid since $t_{0}\left(\Delta \mathrm{F}^{\mathrm{D}}\right.$ lipid), divided by the fraction of $D$ in the incubation medium $\left(F^{D}\right.$ medium $)$ and the time of the incubation (Wegener et al., 2012):

$$
\operatorname{prod}_{\text {lipid }}=\operatorname{conc}_{\text {lipid }} \times \frac{\Delta \mathrm{FD}_{\text {lipid }}}{\mathrm{FD}_{\text {medium }} \times \text { time }}(\text { Equation } 1)
$$


The fractions of $D$ in the lipid derivatives were calculated from the isotope ratios: $F^{D}$ lipid $=$ $R^{D / H} /\left(R^{D / H}+1\right)$, where $R^{D / H}$ is the $D / H$ ratio of the sample determined via GC-IRMS. $F_{\text {medium }}$ was calculated by the known additions of label and pore water volumes of each incubation. The lipid production rates were expressed in $\mathrm{ng}$ lipid $\mathrm{cm}^{-3}$ year ${ }^{-1}$ by assuming a wet density of $0.865 \mathrm{~g} \mathrm{~cm}^{-3}$ and porosity of 0.85 (e.g. Zaccone et al., 2009). The lipid turnover times, expressed in years, were estimated for each incubation condition by dividing the lipid concentration in the corresponding bottle by the respective production rate. The error of production rate and turnover time estimates were propagated from the error of concentration and $\delta D$ values reported above, as well as the error of the $\delta D$ value of the medium $(<5 \%)$.

\subsection{Principal Component Analysis (PCA)}

PCA was performed in order to investigate the signatures of lipid production in the incubations. Trends in the production rates of individual fatty acids and total brGDGTs (i.e., combined IPL and CL forms) among the experimental incubations were assessed by determining the relative contributions of individual lipids to total production (c.f. Fig. S4). Standardized values $(z)$ of these relative production rate data $(x)$ were obtained by subtracting the average $(\bar{x})$ and dividing by the standard deviation (S), i.e. $z=\frac{x-\bar{x}}{S}$; these values were then subjected to PCA (c.f. Zuur et al., 2007). Principal component eigenvalues, loading coefficients, and sample scores were determined using MatLab software (version R2014a). 


\section{RESULTS}

\subsection{Distribution of brGDGT and fatty acid biomarkers in peat}

The concentrations of brGDGTs in the CL fraction were consistently higher (by at least a factor 5) in the deeper catotelm than in the upper acrotelm layer of bog and fen sites, respectively (Fig. 1; Table S3; Student's homoschedastic t-test $p<0.001$ ), consistent with previous studies in peat bogs (Weijers et al., 2006; Huguet et al., 2010; Liu et al., 2010). Structural differences in brGDGTs occur by variation in the number of methyl groups and cyclopentyl rings (Weijers et al., 2007). The same set of brGDGT-CLs (cf. Table S2 for their characteristics) was detected in all the peat samples (Table S3). The relative distribution of brGDGT-CLs was consistent for all samples and time points. That is, no significant differences were observed between acrotelm and catotelm horizons or between bog and fen sites, with acyclic compounds ( $\mathrm{m} / \mathrm{z} 1022,1036$ and 1050) largely predominating over cyclopentane bearing analogues (Figs. $2 \mathrm{~A}$ and 2C; Table S3). BrGDGT-IPLs, assumed to be more representative of living microorganisms than their $\mathrm{CL}$ counterparts, comprised only monoglycosidic headgroups (Table S2), as previously observed in a peat bog from Northern Germany (Liu et al., 2010), and were systematically much less abundant (between ca. 3 and 30 times) than the corresponding CLs (Fig. 1; Table S2, S3), which are typically presumed to be a non-active fossil fraction in peat (e.g. Peterse et al., 2011; Huguet et al., 2013). BrGDGTIPLs were detected in all but two samples (bog-acrotelm- $t_{0}$ and bog-catotelm- $t_{1}$; Table S3). When detected, the relative abundance of brGDGT-IPLs to bulk brGDGT lipids (i.e. CLs + IPLs) ranged from 3-36\%, (Figs. 2A and 2C; Table S3), consistent with values previously reported, e.g. $15-30 \%$ in the Frasne peatland (Huguet et al. 2013) and 9-19 \% in the Saxnäs Mosse (South Sweden; Peterse et al., 2011). 
The abundance of total fatty acids, which summarize compounds from precursor IPLs, diand monoglycerides, and free fatty acids, typically exceeded brGDGT lipids by over an order of magnitude (Fig. 1). Total fatty acid concentrations were similar in the acrotelm and catotelm horizons and showed no consistent variations over the incubation period (Table S3). The fatty acid profiles of all samples were dominated by those containing alkyl chains with 16 carbon atoms (16:0) or monounsaturated forms containing 18 carbon atoms (co-

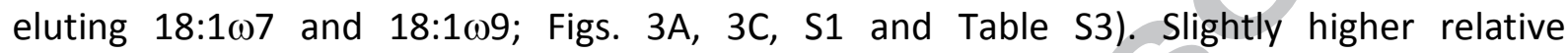
abundances of unsaturated forms of $C_{18}$ fatty acids were typically observed in the one or two month incubations of acrotelm and catotelm samples (35-56\%), in comparison to $t_{0}$ samples (25-41\%; Figs. 3A, 3C and Table S3).

Differences were observed in lipid concentration between sequential time point samples; for example, there was an apparent increase in brGDGT-CLs in the initially aerobic incubation of bog acrotelm between $t_{0}$ and one month (a difference of ca. $0.8 \mu \mathrm{g} \mathrm{g}^{-1}$-humid peat; Table S3). Due to the intrinsic heterogeneity of peat, consisting of stem and root material that is difficult to homogenize, we do not consider the apparent variations in brGDGT concentrations between time points to quantitatively reflect biological production during our experiments. Indeed, the magnitude of concentration differences between time points would invoke production rates that are much higher than observed in cultured Acidobacteria (de Castro et al., 2013) as candidate bacteria for producing brGDGTs, and significant contributions of freshly produced brGDGTs would have yielded a much higher $\delta \mathrm{D}$ value for brGDGT derivatives (cf. Text S1). Stable isotope probing with deuterium provides a more sensitive and accurate estimate of lipid production, as the latter is related to the absolute amount of label $\left(\mathrm{F}^{\mathrm{D}}\right)$ that was incorporated into individual lipid biomarkers.

\subsection{Deuterium incorporation into brGDGTs}


Following ether cleavage of purified $\mathrm{CL}$ and IPL fractions, alkyl chain derivatives of brGDGTs were identified by their characteristic GC/MS spectra (Fig. S2) and corresponded to the dominant forms of brGDGTs found in the peat (i.e. $\mathrm{m} / \mathrm{z} 1022$ and 1036, and to a lesser extent 1050; Tables 1 and S1). The $\delta D$ of brGDGT-CLs in natural peat acrotelm and catotelm (i.e. $t_{0}$ ) ranged from -161 to $-190 \%$ for compound 1 (derived from brGDGTs with $\mathrm{m} / \mathrm{z} 1036$, 1022 or 1020 ) and from -174 to $-199 \%$ for the co-eluting compounds $2 a$ and $2 c$ (derived from brGDGTs with $\mathrm{m} / \mathrm{z}$ 1050, 1036 or 1034 ; Table S4). In the initially oxic incubations of acrotelm samples from the bog and fen sites, the weighted average $\delta D$ of brGDGT-CL derivatives increased to $233 \%$ and $214 \%$ ofter one month and up to $3332 \%$ and $933 \%$ o after two months (i.e. likely under suboxic conditions), respectively (Table S4). In contrast, there was much lower D incorporation during anoxic incubations of bog and fen acrotelm samples after two months (weighted average $\delta D=82 \%$ and $-126 \%$, respectively; Table S4). Bog and fen catotelm incubated anaerobically for 1 month also exhibited low D incorporation into brGDGT-CL derivatives (weighted average $\delta D=-145 \%$ and $-171 \%$, respectively; Table S4), which can partly be explained by the much larger pool size of brGDGTs in the deeper catotelm horizon.

Similarly to brGDGT-CLs, the weighted average $\delta$ D of brGDGT-IPL derivatives reached $2859 \%$ and $2070 \%$ after two months in initially oxic incubations of bog and fen acrotelm, respectively (Fig. 1B; Table S4). Although slightly higher concentrations of brGDGT-IPLs were observed in anoxic versus initially oxic incubations of peat acrotelm after one and two months of incubation (measured via UHPLC-QTOF-MS; Table S3), no alkyl derivatives of brGDGT-IPL from anoxic incubations were detected via GC/IRMS after ether cleavage/reduction. This can, in part, be explained by a much higher $D$ incorporation and 
thus increased IRMS sensitivity during analysis of brGDGT-IPLs harvested from the initially oxic incubations, which is consistent with the trend observed for brGDGT-CLs.

brGDGT-IPLs in the poisoned control incubations (initiated under oxic conditions) were also slightly enriched in $D$, but $\delta D$ values were at least an order of magnitude lower than observed in corresponding live incubations of initially oxic acrotelm (Table S4). The slight D enrichment observed in the poisoned incubations may reflect a partial resistance of brGDGT source microorganisms to the sterilization conditions.

\subsection{Deuterium incorporation into fatty acids}

Fatty acids were also labeled with $D$ and exhibited the highest $D$ incorporation in each sample. After two months of incubation, the weighted average $\delta \mathrm{D}$ of fatty acids surpassed $10,000 \%$ and the highest label of an individual fatty acid reached $62,000 \%$ o (i14:0, bog catotelm; Table S4). Fatty acids harvested from poisoned incubations were also labeled with $D$, such that $D$ incorporation into some of the most abundant fatty acids in the poisoned control was higher than that observed in the live treatments (i.e. 16:0 and 18:1; Table S4). However, compound specific $\delta D$ values were not correlated with the abundance of the corresponding fatty acids (Fig. S3). Given the much lower $\delta D$ values of brGDGTs in the poisoned incubations ( $<89 \%$; Table S4), the high D labeling of fatty acids may be attributed to the resistance of some bacteria to the addition of zinc chloride (e.g. Kelly et al., 1999) and therefore a much lower bacterial competition for substrate, which is more plausible than an abiotic mechanism. Indeed, Kelly et al., (1999) demonstrated that application of $\mathrm{ZnCl}_{2}$ poison induced changes in the fatty acid profiles of soil incubations, resulting in significantly higher relative amounts of fatty acids 18:2, Me18:0, and Me17:0. Because D incorporation into fatty 
acids in the poisoned control likely resulted from biological activity, $\Delta \mathrm{F}^{\mathrm{D}}$ values of fatty acids were determined relative to $t_{0}$ values rather than the poisoned control.

\section{4. ${ }^{13} \mathrm{C}$ incorporation into bacterial lipids}

After two months, the $\delta^{13} \mathrm{C}$ values of all brGDGT derivatives harvested from the initially oxic and the anoxic incubations of peat acrotelm were $<-28 \%$ (Table S5), indicating that DIC did not serve as a primary carbon substrate for brGDGT biosynthesis. Similarly to brGDGTs, the $\delta^{13} \mathrm{C}$ of individual fatty acids remained invariably low after two months of incubation $(<-$ 21\%; Table S5), indicating that DIC was not a major carbon source for the biosynthesis of fatty acids in the acrotelm or catotelm horizons.

\subsection{Lipid production rates}

D incorporation into brGDGT-CLs converted to total production rates (i.e. for the complete series of brGDGT alkyl chains) ranged from $16-83 \mathrm{ng} \mathrm{cm}^{-3} \mathrm{y}^{-1}$ in the initially oxic incubations of bog and fen acrotelm, whereas corresponding rates in the anoxic acrotelm incubations were roughly an order of magnitude lower $\left(<3 \mathrm{ng} \mathrm{cm}^{-3} \mathrm{y}^{-1}\right.$; Figs. $2 \mathrm{~B}$ and $\left.2 \mathrm{D}\right)$. In the deeper, anoxic bog and fen catotelm, brGDGT-CL production rates were lower (6.6 and $7.1 \mathrm{ng} \mathrm{cm}^{-3} \mathrm{y}^{-1}$, respectively) than in the initially oxic incubations of surface acrotelm, but higher than observed in the anoxic acrotelm treatments (Figs. 2B and 2D). Compound 1 contributed to the majority of brGDGT-CL production in all incubations ( $57 \%$ on average; Figs. 2B and 2D). Production of brGDGT-IPLs was 4.0 and $2.2 \mathrm{ng} \mathrm{cm}^{-3} \mathrm{y}^{-1}$ in the initially oxic bog and fen acrotelm, respectively, and accounted for $<4 \%$ of total brGDGT production (Figs. 2B and 2D).

Total fatty acid production rates approached or exceeded $2 \mu \mathrm{g} \mathrm{cm}^{-3} \mathrm{y}^{-1}$ in both initially oxic and anoxic incubations (Figs. 3B and 3D), which is similar to rates reported for sulfate 
reducing sediments in the Baltic Sea (ca. $3 \mu \mathrm{g} \mathrm{cm}^{-3} \mathrm{y}^{-1}$; Wegener et al., 2012). More conservative estimates of fatty acid production, based on D enrichments normalized to the poisoned control rather than $t_{0}$ values, remain above $1 \mu \mathrm{g} \mathrm{cm}^{-3} \mathrm{y}^{-1}$ and $>40$-fold higher than brGDGT-CLs. The different incubation treatments exhibited alternative patterns in the relative production of individual fatty acids, with relatively enhanced production rates of

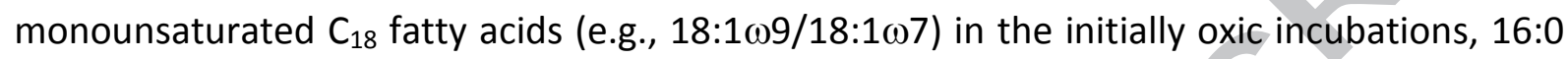
and $16: 1 \omega 9 / 16: 1 \omega 7$ in the anoxic acrotelm, and 14:0 in the bog catotelm (Figs. 3B, 3D and S4).

\subsection{PCA of bacterial lipid production rates}

The first three principal components (PC) accounted for over $73 \%$ of the variability in the lipid production rates. Four clusters of bacterial lipid biosynthesis were identified, each corresponding to different experimental treatments (Fig. 4; Table 1): the initially oxic acrotelm samples incubated for one month (cluster A) or two months (cluster B); anoxic acrotelm samples incubated for two months (cluster C); and the bog catotelm sample (cluster D). PC1 identified the relatively enhanced production of short, saturated, straight chain fatty acids $14: 0$ and 15:0 in the bog catotelm (cluster D; Table 1; cf. Figs. 3B, S4), which separated this cluster from the acrotelm incubations (Fig. 4). Notably, bacterial lipid production rates were much higher in the bog versus fen catotelm, largely resulting from the increased biosynthesis of 14:0 (Fig. 3B). The gradient along PC2 separated the initially oxic versus anoxic acrotelm incubations (Fig. 4). Initially oxic incubations exhibited preferential production of unsaturated $\mathrm{C}_{18}$ fatty acids (cluster $\mathrm{A}$ ), a co-eluting peak that included 18:3,

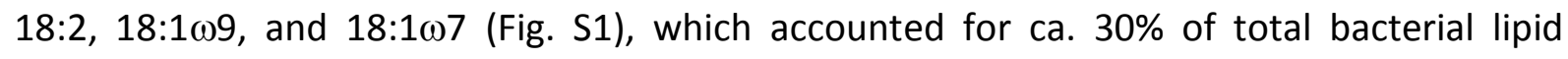
production (Fig. S4). The production of monounsaturated $C_{16}$ fatty acids (16:109 and 
16:1 $\omega 7$ ) was relatively enhanced in the anoxic acrotelm incubations (cluster C), increasing to roughly $12 \%$ of total bacterial lipid production in both bog and fen samples (Fig. S4). The initially oxic acrotelm samples incubated for two months were separated along PC3 and grouped with the production of brGDGTs and two branched fatty acids (cluster B; Fig. 4). The summed production of cluster B lipids was always $<3 \%$ of total bacterial lipid production in bog and fen samples, except for the initially oxic acrotelm samples incubated for two months, where they contributed to $5.4 \%$ and $6.7 \%$ of total bacterial lipid production, respectively (Fig. 4, S4).

\section{DISCUSSION}

\subsection{Constraints on the metabolism of brGDGT source organisms}

Until now, based on the much higher abundance of brGDGTs in the permanently waterlogged catotelm in comparison to the upper, periodically oxic acrotelm of peat bogs, brGDGT source microorganisms were mainly suggested to be anaerobic bacteria (e.g., Weijers et al., 2006). However, brGDGTs have been detected in a wide variety of environments, notably in aerobic settings such as dry and well-drained soils (e.g. Loomis et al., 2011; Menges et al., 2014), rivers (e.g. De Jonge et al., 2014) and in three aerobic strains of the phylum Acidobacteria (Sinninghe Damsté et al., 2011). In the current study, the high D incorporation, replicated in incubations of both bog and fen acrotelm samples (Table S4), demonstrated that both brGDGT-CLs and -IPLs were actively produced in the treatments that began under oxic conditions (up to $87 \mathrm{ng} \mathrm{cm}^{-3} \mathrm{y}^{-1}$; Figs. 2B and 2D). If we correct the rates of lipid production for biosynthetic isotopic fractionation of $D$ (i.e., the discrimination of the heavy isotopes during lipid formation) by invoking the maximum water-lipid fractionation factor reported for tetraether lipids $\left(\alpha_{\text {H2O/Lipid }}=1.45\right.$; Wegener et al., 2012$)$, brGDGT-CL 
production rates in the initially oxic acrotelm would increase to $130 \mathrm{ng} \mathrm{cm}^{-3} \mathrm{y}^{-1}$. Considering the strong signal of D incorporation and thus evidence of brGDGT production, the lack of corresponding ${ }^{13} \mathrm{C}$ incorporation (Table S5) strongly supports the prevailing hypothesis that brGDGT-producing bacteria are heterotrophs, as previously suggested in organo-mineral soils (Oppermann et al., 2010; Weijers et al., 2010; Huguet et al., 2012). Similarly, the lack of ${ }^{13} \mathrm{C}$ incorporation into fatty acids suggests that the active bacteria were predominantly heterotrophs. While it is possible that our experimental conditions discriminated against autotrophs among the natural bacterial community, our findings are consistent with the prevalence of heterotrophic microorganisms in peatlands, which represented $78 \%$ to $97 \%$ of the total microbial biomass in five Sphagnum-dominated peatlands across Europe (e.g. Mitchell et al., 2003).

The generally lower brGDGT production rates observed during the anoxic incubations of the acrotelm and catotelm than during the oxic incubations of the acrotelm (Figs. 2B and 2D) suggest that oxic conditions and/or the transition from oxic to anoxic conditions (i.e. suboxic conditions) could have created a geochemical environment that favored the growth of brGDGT source microorganisms. The similar brGDGT production rates in anoxic incubations of acrotelm and catotelm layers suggest that the quality of organic substrate cannot explain the enhanced rates observed in initially oxic acrotelm incubations. It should be noted that in the initially oxic acrotelm samples, production rates of brGDGT-CLs after 2 months were higher than after 1 month, corresponding to 3- and 6-fold increases during the second month of incubation in fen and bog incubations, respectively (i.e. under suboxic to anoxic conditions, as the oxygen was likely totally consumed in the incubations after 22 days; Table S1). This suggests that brGDGT source microorganisms preferentially grow under the transition from oxic to anoxic conditions, as also supported by the extremely retarded 
production of brGDGTs in anoxic acrotelm incubations (0.6-3 $\mathrm{ng} \mathrm{cm}^{-3} \mathrm{y}^{-1}$; Figs. 2B and 2D) in comparison to the initially oxic acrotelm after two months of incubation. This is consistent with the findings of Liu et al. (2014), who demonstrated a subsurface peak in brGDGT concentration at the base of the oxycline (i.e. the transition from oxic to suboxic waters) in the water column of the Black Sea.

\subsection{Turnover of brGDGTs and fatty acids in peat: biogeochemical implications}

Relative to their CL counterparts, brGDGT-IPL production was roughly 20-fold slower in bog and fen acrotelm (Figs. 2B and 2D). This result seemingly conflicts with the relatively high turnover of brGDGT-IPLs in peat as suggested by Liu et al. (2010), who observed that the accumulation of brGDGT-IPLs was much lower than isoprenoidal GDGT-IPLs, even though concentrations of brGDGT-CLs exceeded isoprenoidal GDGT-CLs by an order of magnitude. The low production rates of brGDGT-IPLs in the current study could be explained by the high turnover of a labile portion of brGDGT-IPLs (e.g. phospholipids), which were quickly converted to CLs and hence did not accumulate. This would result in low brGDGT-IPL abundance and similarly low apparent $D$ incorporation, as a large fraction of non-labeled brGDGT-IPL 'fossils' effectively dilute the dD value. It is also possible that brGDGT-IPLs were lost during extraction or separation steps (e.g. Pitcher et al., 2009; Lengger et al., 2012), which could have artificially led to an underestimation of IPL production rates. BrGDGT-CLS could also be produced in such form by microorganisms to fulfill biological functions in the membranes (Meador et al., 2014). Despite differences in production rate, the turnover times $(\tau)$ of brGDGT-CLs (8-41 y) and brGDGT-IPLs (11-14 y) were similar in all initially oxic incubations (Table 2), suggesting that both forms of brGDGT lipids are recent products of microbial activity in the surficial peat layers. 
The relatively high activity of brGDGT source organisms in the peat surface and the associated rapid turnover of brGDGTs (Table 2) are consistent with the rapid adjustment of brGDGT-IPLs to temperature changes previously observed in peat (Huguet et al., 2013, 2014). We note that the $\tau$ estimates of brGDGT lipids in peat measured by the present study, which correspond to the time necessary to refresh the whole lipid pool at $12^{\circ} \mathrm{C}$, are longer than the time required for Huguet et al. $(2013,2014)$ to detect a change in brGDGT distributions in peat incubated in the field or in the laboratory at $15^{\circ} \mathrm{C}$ (corresponding to a partial replacement of the lipid pool), but in agreement with the $\tau$ times measured in organo-mineral soils via field labeling experiments ( $\tau=18 \mathrm{y}$; Weijers et al., 2010). In any case, all the studies consistently suggest that brGDGTs, and thus the paleo-proxies that implement these biomarkers, integrate microbial and environmental processes on decadal time scales in a variety of terrestrial environments. The lower production rate documented in the catotelm during the current study is incongruent with the higher abundance of brGDGTs usually observed in this horizon of peat bogs (e.g. Weijers et al., 2006; Huguet et al., 2010). This contrast is likely to result from strongly retarded degradation of brGDGTs and thus slower turnover, leading to the accumulation of these compounds in the anoxic catotelm. It should be noted that brGDGT turnover time in the acrotelm differed by more than an order of magnitude under initially oxic vs. anoxic conditions (Table 2), concordant with a high aerobic potential for brGDGT degradation.

Production of total fatty acids was $70-$ to $800-$ fold higher than that of brGDGT-CLs in initially oxic incubations of acrotelm peat and roughly three orders of magnitude higher in the anoxic catotelm (Fig. 3B). Total fatty acid turnover times were correspondingly 2- to 14fold faster than those of brGDGT-CLs in the acrotelm and $>50$-fold faster in the catotelm (Table 2). This suggests that either the source organisms of brGDGTs are low-abundance 
members of the microbial community in peat or that brGDGTs constitute only a small fraction of the microbial cell membrane in comparison to fatty acids, consistent with the lipid profile of certain Acidobacteria (Sinninghe Damsté et al., 2011). Therefore, despite the high abundances of brGDGTs in peat, their source organisms do not have to be dominant members of the peat bacterial community, as previously suggested (Weijers et al., 2009).

\subsection{Production regimes of fatty acids and brGDGTs in peat}

PCA of fatty acid concentrations in peatland was previously applied to assign individual compounds to distinct microbial production regimes that occur across gradients of wet to dry as well as surface to subsurface realms (Sundh et al., 1997). The accumulation of fatty acids and brGDGTs in peat are likely uncoupled, owing to the higher reactivity of fatty acid ester linkages versus the more stable ether bonds of GDGTs. In contrast to concentration data, direct measurements of bacterial lipid production rates determined by $D$ labeling are unbiased by the expected differences in lipid preservation. PCA was therefore applied to the relative production rates of bacterial lipids to collectively determine signatures of fatty acid and brGDGT biosynthesis among the experimental treatments (Fig. 4; Table 1).

The clustering of initially oxic acrotelm incubations (clusters A and B) suggests that the oxic conditions and/or transition from oxic to anoxic conditions may have stimulated the production of specific lipid biomarkers, the signals of which were integrated over one or two month intervals (i.e. clusters $A$ and $B$, respectively). The microbial sources of lipids associated with clusters $A$ and $B$ are thus presumably aerobes or facultative aerobes, who may be selected for in the acrotelm by oscillations of the water table. In particular, brGDGT production clustered with the production of two branched fatty acids: Me-br15 and ai17:0/17:1 18 (cluster B; Table 1; Fig. 4), the latter being a co-eluting peak for which we 
were unable to resolve the $D$ labeling of terminally branched ai17:0 versus that of the straight chain unsaturated 17:108 biomarker (Figure S1). Production rates of cluster B branched fatty acids were positively correlated with that of brGDGTs ( $p<0.001$; Fig. 5) among the incubated peat samples (excluding one outlier and poisoned controls incubations; $n=7$ ). The similar production patterns of these bacterial lipids suggest that microbial sources of brGDGTs might also produce the branched fatty acids Me-br15 and ai17:0. It follows that these branched fatty acids may serve as precursors for brGDGT biosynthesis. It should be noted that, based solely on a model hypothesized for isoprenoidal GDGT biosynthesis, Weijers et al. (2006) proposed a biosynthetic pathway for brGDGTs invoking the condensation of ether-linked isopentadecane alkyl chains, which correspond to the branched alkyl chain of $i 17: 0$. In soils, only minor amounts of ai17:0 fatty acids were detected in the cell membrane of some of the Acidobacteria strains, a potential source for brGDGTs, whereas i15:0 was one of the dominant fatty acids (Sinninghe Damsté et al., 2011, 2014).

The lipids arising from strictly aerobic production should have grouped within cluster A, as their contribution was presumably higher in the initially oxic acrotelm samples that were incubated for only one month and thus integrated a relatively shorter period of anaerobic production compared to all other treatments. Notably, polyunsaturated $\mathrm{C}_{18}$ fatty acids (i.e. 18:3 and 18:2) grouped with cluster A, and were previously attributed to the shoots of Sphagnum mosses and production by cyanobacteria as well as fungi in peat surface horizons (0-10 cm; Sundh et al., 1997). These polyunsaturated forms co-eluted with monounsaturated

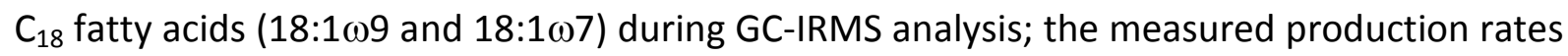
thus integrated the mixed signal of these compounds, the latter being relatively more abundant (Fig. S1). Sundh et al. (1997) suggested that monounsaturated fatty acids most 
likely indicated the production of aerobic bacteria in peatland samples, although their distribution patterns were not uniform. The terminally branched fatty acids i17:0/10Me16:0 and i17:1 were also associated with cluster $\mathrm{A}$ and could have derived from the production of anaerobic bacteria (e.g., Sundh et al., 1997; Quezada et al., 2007), sulfate-reducing bacteria in particular (e.g., Dowling et al., 1986; Dzierzewicz et al., 1996).

The clusters $C$ and $D$ distinguish strictly anaerobic lipid production in acrotelm and bog catotelm, respectively (Fig. 4), with the former comprising both monounsaturated and terminally branched fatty acids (16:1 $\omega 9 / 16: 1 \omega 7$ representing the majority of production) and the latter comprising only short, saturated, straight chain fatty acids (Table 1). The distinct grouping of anoxic acrotelm versus anoxic catotelm incubations further suggests that distinct anaerobic microbial communities were active in the incubations of the two peat layers, as also indicated by the higher rates of brGDGT production in the anoxic catotelm vs. anoxic acrotelm incubations (Figs. 3B and 3D).

\section{CONCLUSIONS}

This stable isotope probing experiment has demonstrated for the first time that brGDGTproducing bacteria in peat are more active in the periodically aerobic acrotelm than in the anoxic catotelm. Our results suggest that these organisms preferentially grow under suboxic conditions, possibly as facultative aerobes. The fact that little to no ${ }^{13} \mathrm{C}$ from inorganic carbon was introduced into brGDGTs during our dual label experiments strongly suggests that their producers are heterotrophs. Given that brGDGT production can only account for approximately $<1.5 \%$ of total bacterial lipid production, their producers may represent only a minority population, despite the typically high brGDGT concentrations observed in peat. Multivariate analysis of bacterial lipid production rates identified two branched fatty acids 
(Me-br15 and ai17:0) that were associated with brGDGT production and may serve as precursors for brGDGT biosynthesis. The turnover times of brGDGT-CLs (8-41 y) and brGDGTIPLs (11-14 y) in the acrotelm peat incubations are consistent with those previously measured in organo-mineral soils, suggesting that brGDGTs turn over on timescales of decades in terrestrial environments. Much higher turnover times (320-510 y) were observed in the catotelm (i.e. in the absence of $\mathrm{O}_{2}$ ), which indicates that brGDGTs are more easily degraded under aerobic conditions.

\section{Acknowledgements}

T.B. Meador, M. Könneke, and K-U. Hinrichs as well as laboratory analyses were supported by the Deutsche Forschungsgemeinschaft through Gottfried Wilhelm Leibniz Award awarded to K-U. Hinrichs (grant \# HI 616-14). Julius Lipp and Lars Wörmer facilitated QTOF/MS analyses and J. Lipp provided GDGT laboratory standards for lipid quantification. Marcus Elvert assisted with identification of fatty acid derivatives. Xavier Prieto and Jenny Wendt are acknowledged for their support of GC and IRMS analyses. CNRS/INSU is thanked for the funding of the SNO Tourbières. We thank D. Naafs and two anonymous reviewers for constructive comments which helped to improve the manuscript.

\section{References}

Ayari A., Yang H., Wiesenberg G.L.B. and Xie S. (2013) Distribution of archaeal and bacterial tetraether membrane lipids rhizosphere-root systems in soils and their implications for paleoclimate assessment. Geochem. J. 47, 337-347.

Becker K.W., Lipp J.S., Zhu C., Liu X.-L. and Hinrichs K.-U. (2013) An improved method for the analysis of archaeal and bacterial ether core lipids. Org. Geochem. 61, 34-44. 
Blume E., Bischoff M., Reichert J. M., Moorman T., Konopka A. and Turco R. F. (2002) Surface and subsurface microbial biomass, community structure and metabolic activity as a function of soil depth and season. Appl. Soil Ecol. 20, 171-181.

Boschker H.T.S., Nold S.C., Wellsbury P., Bos D., de Graaf W., Pel R. et al. (1998) Direct linking of microbial populations to specific biogeochemical processes by ${ }^{13} \mathrm{C}$-labelling of biomarkers. Nature 392, 801-805.

Colcord D.E., Cadieux S.B., Brassell S.C., Castañeda I.S., Pratt L.M., White J.R. (2015) Assessment of branched GDGTs as temperature proxies in sedimentary records from several small lakes in southwestern Greenland. Org. Geochem. 82, 33-41.

D’Angelo B., Gogo S., Laggoun-Défarge F., Le Moing F., Jégou F., Guimbaud C. (2016) Soil temperature synchronisation improves representation of diel variability of ecosystem respiration in Sphagnum peatlands. Agric. For. Meteorol. 223, 95-102.

De Jonge C., Stadnitskaia A., Hopmans E.C., Cherkashov G., Fedotov A., Sinninghe Damsté J.S. (2014) In situ produced branched glycerol dialkyl glycerol tetraethers in suspended particulate matter from the Yenisei River, Eastern Siberia. Geochim. Cosmochim. Acta 125, 476-491.

De Rosa M., Gambacorta A. (1988) The lipids of archaeabacteria. Prog. Lipid Res. 27, 153175.

Delarue F., Laggoun-Défarge F., Buttler A., Gogo S., Jassey V. and Disnar J.-R. (2011) Effects of short-term ecosystem experimental warming on water-extractable organic matter in an ombrotrophic Sphagnum-peatland. Org. Geochem. 42, 1016-1024.

Dowling N.J.E., Widdel F., and White D. (1986) Phospholipid ester-linked fatty acid biomarkers of acetate-oxidizing sulphate-reducers and other sulphide-forming bacteria. J. Gen. Microbiol. 132, 1815-1825.

Dzierzewicz Z., Cwalina B., Kurkiewicz S., Chodurek E., Wilczok T. (1996) Intraspecies variability of cellular fatty acids among soil and intestinal strains of Desulfovibrio desulfuricans. Appl. Environ. Microbiol. 62, 3360-3365.

Huguet A., Fosse C., Laggoun-Défarge F., Toussaint M.-L. and Derenne S. (2010) Occurrence and distribution of glycerol dialkyl glycerol tetraethers in a French peat bog. Org. Geochem. 41, 559-572.

Huguet A., Wiesenberg G.L.B., Gocke M., Fosse C. and Derenne S. (2012) Branched tetraether membrane lipids associated with rhizoliths in loess: rhizomicrobial overprinting of initial biomarker record. Org. Geochem. 43, 12-19.

Huguet A., Fosse C., Laggoun-Défarge F., Delarue F., and Derenne S. (2013a) Effects of a short-term experimental microclimate warming on the abundance and distribution of branched GDGTs in a French peatland. Geochim. Cosmochim. Acta 105, 294-315. 
Huguet A., Gocke M., Derenne S., Fosse C. and Wiesenberg G.L.B. (2013b) Root-associated branched tetraether source microorganisms may reduce estimated paleotemperatures in subsoil. Chem. Geol. 356, 1-10.

Huguet A., Francez A.-J., Jusselme M.D., Fosse C. and Derenne S. (2014) A climatic chamber experiment to test the short term effect of increasing temperature on branched GDGT distribution in Sphagnum peat. Org. Geochem. 73, 109-112.

Huguet C., Hopmans E.C., Febo-Ayala W., Thompson D.H., Sinninghe Damsté J.S. and Schouten S. (2006) An improved method to determine the absolute abundance of glycerol dibiphytanyl tetraether lipids. Org. Geochem. 37, 1036-1041.

Jahn U., Summons R., Sturt H., Grosjean E. and Huber H. (2004) Composition of the lipids of Nanoarchaeum equitans and their origin from its host Ignicoccus sp. strain KIN4/I. Arch. Microbiol. 182, 404-413.

Jones R.T., Robeson M.S., Lauber C.L., Hamady M., Knight R., Fierer N. (2009) A comprehensive survey of soil acidobacterial diversity using pyrosequencing and clone library analyses. ISME J. 3, 442-453.

Kaneda T. (1991) Iso- and anteiso-fatty acids in Bacteria: Biosynthesis, function, and taxonomic significance. Microbiol. Mol. Biol. Rev. 55, 288-302.

Kellermann M.Y., Wegener G., Elvert M., Yoshinaga M.Y., Lin Y.-S., Holler T., Prieto Mollar X., Knittel K. and Hinrichs K.-U. (2012) Autotrophy as a predominant mode of carbon fixation in anoxic methane-oxidizing communities. Proc. Natl. Acad. Sci. USA 109, 19321-19326.

Kelly J.J., Häggblom M., Tate III R.L. (1999). Changes in soil microbial communities over time resulting from one time application of zinc: a laboratory microcosm study. Soil Biol. Biochem. 31, 1455-1465.

Kopf S.H., Sessions A.L., Cowley E.S., Reyes C., Van Sambeek L., Hu Y., Orphan V.J., Kato R., Newman D.K. (2016) Trace incorporation of heavy water reveals slow and heterogeneous pathogen growth rates in cystic fibrosis sputum Proc. Natl. Acad. Sci. USA 113, E110-E116.

Lengger S.K., Hopmans E.C., Sinninghe Damsté J.S., Schouten S. (2012) Comparison of extraction and work up techniques for analysis of core and intact polar tetraether lipids from sedimentary environments. Org. Geochem. 47, 34-40.

Loomis S.E., Russell J.M., Lamb H.F. (2015) Northeast African temperature variability since the Late Pleistocene. Palaeogeogr. Palaeoclimatol. Palaeoecol. 423, 80-90.

Lin Y.S., Lipp J.S., Elvert M., Holler T., Hinrichs K.-U. (2012) Assessing production of the ubiquitous archaeal diglycosy tetraether lipids in marine subsurface sediment using intramolecular stable isotope probing. Environ. Microbiol. 15, 1634-1646. 
Liu X-L., Leider A., Gillespie A., Gröger J., Versteegh G.J.M., Hinrichs K-U. (2010) Identification of polar lipid precursors of the ubiquitous branched GDGT orphan lipids in a peat bog in Northern Germany. Org. Geochem. 41, 653-660.

Liu X-L., Zhu C., Wakeham S.G., Hinrichs K-U. (2014) In situ production of branched glycerol dialkyl glycerol tetraethers in anoxic marine water columns. Mar. Chem. 166, 1-8.

Loomis S.E., Russell J.M. and Sinninghe Damsté J.S. (2011) Distributions of branched GDGTs in soils and lake sediments from western Uganda: Implications for a lacustrine paleothermometer. Org. Geochem. 42, 739-751.

Meador T.B., Zhu C., Elling F., Könneke M. and Hinrichs K-U. (2014) Identification of isoprenoidal glycosidic glycerol dibiphytanol diethers and indications for their biosynthetic origin. Org. Geochem. 69, 70-75.

Meador T.B., Bowles M., Lazar C.S., Zhu C., Teske A. and Hinrichs K.-U. (2015) The archaeal lipidome in estuarine sediment dominated by members of the Miscellaneous Crenarchaeotal Group. Environ. Microbiol. 17, 2441-2458.

Menges J., Huguet C., Alcañiz J.M., Fietz S., Sachse D. and Rosell-Melé A. (2014) Water availability determines branched glycerol dialkyl glycerol tetraether distributions in soils of the Iberian Peninsula. Biogeosciences 11, 2571-2581.

Mitchell E.A., Gilbert D., Buttler A., Amblard C., Grosvernier P., Gobat J.M. (2003) Structure of microbial communities in Sphagnum peatlands and effect of carbon dioxide treatment. Microb. Ecol. 46, 187-199.

Oppermann B.I., Michaelis W., Blumenberg M., Frerichs J., Schulz H.-M., Schippers A., Beaubien S.E. and Krüger M. (2010) Soil microbial community changes as a result of longterm exposure to a natural $\mathrm{CO}_{2}$ vent. Geochim. Cosmochim. Acta 74, 2697-2716.

Pancost R.D. and Sinninghe Damsté J.S. (2003) Carbon isotopic compositions of prokaryotic lipid as tracers of carbon cycling in diverse settings. Chem. Geol. 195, 29-58.

Pankratov T.A., Serkebaeva Y.M., Kulichevskaya I.S., Liesack W., Dedysh S.N. (2008) Substrate-induced growth and isolation of Acidobacteria from acidic Sphagnum peat. ISME J. 2, 551-560.

Penger, J., Conrad, R., Blaser, M. (2014) Stable carbon isotope fractionation of six strongly fractionating microorganisms is not affected by growth temperature under laboratory conditions. Geochim. Cosmochim. Acta 140, 95-105.

Peterse F., Hopmans E.C., Schouten S., Mets A., Rijpstra W.I.C., Sinninghe Damsté J.S. (2011) Identification and distribution of intact polar branched tetraether lipids in peat and soil. Org. Geochem. 42, 1007-1015. 
Peterse F., Martinez-Garcia A., Zhou B., Beets C.J., Prins M.A., Zheng H. and Eglinton T.I. (2014) Molecular records of continental air temperature and monsoon precipitation variability in East Asia spanning the past 130,000 years. Quat. Sci. Rev. 83, 76-82.

Pitcher A., Hopmans E.C., Schouten S., Sinninghe Damsté J.S. (2009) Separation of core and intact polar archael tetraether lipids using silica columns: Insights into living and fossil biomass contributions. Org. Geochem. 40, 12-19.

Quezada M., Buitrón G., Moreno-Andrade I., Moreno G., and López-Marin L. (2007) The use of fatty acid methyl esters as biomarkers to determine aerobic, facultatively aerobic and anaerobic communities in wastewater treatment systems. FEMS Microbiol. Lett. 266, 7582.

Reeves E.P., Seewald J.S., Sylva S.P. (2012) Hydrogen isotope exchange between $n$-alkanes and water under hydrothermal conditions. Geochim. Cosmochim. Acta 77, 582-599.

Schouten S., Hopmans E.C., Sinninghe Damsté J.S. (2013) The organic geochemistry of glycerol dialkyl glycerol tetraether lipids: A review. Org. Geochem. 54, 19-61.

Sessions A.L., Sylva S.P., Summons R.E., Hayes J.M. (2004) Isotopic exchange of carbonbound hydrogen over geologic timescales. Geochim. Cosmochim. Acta 68, 1545-1559.

Sinninghe Damsté J.S., Hopmans E.C., Pancost R.D., Schouten S. and Geenevasen J.A.J. (2000) Newly discovered nonisoprenoid glycerol dialkyl glycerol tetraether lipids in sediments. Chem. Commun. 17, 1683-1684.

Sinninghe Damsté J.S., Rijpstra W.I.C., Hopmans E.C., Weijers J.W.H., Foesel B.U., Overmann J. and Dedysh S.N. (2011) 13,16-Dimethyl Octacosanedioic Acid (iso-Diabolic Acid), a Common Membrane-Spanning Lipid of Acidobacteria Subdivisions 1 and 3. Appl. Environ. Microbiol. 77, 4147-4154.

Sinninghe Damsté J.S., Rijpstra W.I.C., Hopmans E.C., Foesel B.U., Wüst P.K., Overmann J., Tank M., Bryant D.A., Dunfield P.F., Houghton K. and Stott M.B. (2014) Ether- and EsterBound iso-Diabolic Acid and Other Lipids in Members of Acidobacteria Subdivision 4. Appl. Environ. Microbiol. 80, 5207-5218.

Sturt H.F., Summons R.E, Smith K, Elvert M. and Hinrichs K.U. (2004) Intact polar membrane lipids in prokaryotes and sediments deciphered by high-performance liquid chromatography/electrospray ionization multistage mass spectrometry--new biomarkers for biogeochemistry and microbial ecology. Rapid Commun. Mass Spectrom. 18, 617-628.

Sundh I., Nilsson M., Borgå P. (1997) Variation in microbial community structure in two boreal peatlands as determined by analysis of phospholipid fatty acid profiles. Appl. Environ. Microbiol. 63, 1476-1482. 
Tierney J.E., Russell J.M., Eggermont H., Hopmans E.C., Verschuren D. and Sinninghe Damsté J.S. (2010) Environmental controls on branched tetraether lipid distributions in tropical East African lake sediments. Geochim. Cosmochim. Acta 74, 4902-4918.

Weber Y., De Jonge C., Rijpstra W.I.C., Hopmans E.C., Stadnitskaia A., Schubert C.J., Lehman M.F., Sinninghe Damsté J.S., Niemann H. (2015) Identification and carbon isotope composition of a novel branched GDGT isomer in lake sediments: Evidence for lacustrine branched GDGT production. Geochim. Cosmochim. Acta 154, 118-129.

Wegener G., Bausch M., Holler T., Thang N.M., Prieto Mollar S., Kellermann M.Y., Hinrichs K.U. and Boetius A. (2012) Assessing sub-seafloor microbial activity by combined stable isotope probing with deuterated water and 13C-bicarbonate. Environ. Microbiol. 14, 15171527.

Weijers J.W.H., Schouten S., Hopmans E.C., Geenevasen J.A.J., David O.R.P., Coleman J.M., Pancost R.D. and Sinninghe Damsté J.S. (2006) Membrane lipids of mesophillic anoxic bacteria thriving in peats have typical archaeal traits. Environ. Microbiol. 8, 648-657.

Weijers J.W.H., Schouten S., van den Donker J.C., Hopmans E.C. and Sinninghe Damsté J.S. (2007) Environmental controls on bacterial tetraether membrane lipid distribution in soils. Geochim. Cosmochim. Acta 71, 703-713.

Weijers J.W.H., Panoto E., van Bleijswijk J., Schouten S., Rijpstra I.C., Balk M., Stams A.J.M. and Sinninghe Damsté J.S. (2009) Constraints on the biological source(s) of the orphan branched tetraether membrane lipids. Geomicrobiol. J. 26, 402-414.

Weijers J.W.H.,Wiesenberg G.L.B., Bol R., Hopmans E.C. and Pancost R.D. (2010) Carbon isotopic composition of branched tetraether membrane lipids in soils suggest a rapid turnover and a heterotrophic lifestyle of their source organism(s). Biogeosciences 7, 29592973.

Weijers J.W.H., Steinmann P., Hopmans E.C., Schouten S. and Sinninghe Damsté J.S. (2011) Bacterial tetraether membrane lipids in peat and coal: Testing the MBT-CBT temperature proxy for climate reconstruction. Org. Geochem. 42, 477-486.

Zaccone C., D’Orazio V., Shotyk W., Miano T.M., (2009) Chemical and spectroscopic investigation of porewater and aqueous extracts of corresponding peat samples throughout a bog core (Jura Mountains, Switzerland). J. Soils Sediments 9, 443-456.

Zell C., Kim J.-H., Hollander D., Lorenzoni L., Baker P., Guizan Silva C., Nittrouer C. and Sinninghe Damsté J.S. (2014) Sources and distributions of branched and isoprenoid tetraether lipids on the Amazon shelf and fan: Implications for the use of GDGT-based proxies in marine sediments. Geochim. Cosmochim. Acta 139, 293-312. 
Zheng Y., Li Q., Wang,Z., Naafs B.D.A., Yu X. and Pancost R.D. (2015) Peatland GDGT records of Holocene climatic and biogeochemical responses to the Asian Monsoon. Org. Geochem. 87, 86-95.

Zhu C., Meador T.B., Dummann W., Hinrichs K-U. (2014) Identification of unusual butanetriol dialkyl glycerol tetraether and pentanetriol dialkyl glycerol tetraether lipids in marine sediments. Rapid Commun. Mass Spectrom. 28, 332-338.

Zuur A.F., leno E.N, Smith, G.M. (2007) Analysing ecological data. Springer, New York. 


\section{Figure Captions}

Figure 1. Bacterial lipid concentrations in the bog and fen acrotelm (open symbols) and catotelm horizons (filled symbols).

Figure 2. Fractional abundance of brGDGT lipids in bog (A) and fen (C) $t_{0}$ samples and all treatments ( $P=$ poisoned control). The colors refer to brGDGT ions whose $m / z$ are noted in the legend below (cf. Table S2). Production rates of brGDGT alkyl chains (cf. Fig. S2) after one $\left(t_{1}\right)$ or two month $\left(t_{2}\right)$ incubation of bog (B) or fen (C) acrotelm and catotelm. Error bars refer to the propagated error in $\delta \mathrm{D}$ and concentration measurements.

Figure 3. Fractional abundance of fatty acids in bog (A) and fen (C) $t_{0}$ samples and all treatments $\left(t_{1}=\right.$ one month; $t_{2}=$ two months; $P=$ poisoned control). Fatty acid production rates after one or two month incubation of bog (B) or fen (D) acrotelm and catotelm. The percentage contribution of brGDGTs to total fatty acid abundance or production is indicated by the black lines and symbols in panels A-D. Error bars refer to the propagated error in $\delta D$ and concentration measurements.

Figure 4. Principal component analysis (PCA) of fractional contributions to total fatty acid and brGDGT production. Shown are biplots of the first three PC axes with their percentages of variance in parentheses. Lipid identification codes are provided in the table on the right of the figure and plotted on the PC axes. Bog (circles) and fen samples (squares) that were initiated under oxic conditions (blue) and harvested at $t_{2}$ grouped apart from those from $t_{1}$ (green) as well as anoxic incubations of the acrotelm (pink) and catotelm (red). The dotted ovals identify four clusters (A-D) of samples and bacterial lipids (see text) which are color coded according to their grouping; brGDGTs grouped with oxic acrotelm incubations harvested at $\mathrm{t} 2$ (Cluster $\mathrm{B}$; blue).

Figure 5. Comparison of cluster B (cf. Fig. 4) brGDGT and branched fatty acid production rates among incubations of peat acrotelm (open symbols) and catotelm (filled symbols) collected from bog (circles) and fen sites (diamonds). The results from poisoned incubations were excluded for this comparison.

Table 1. Bacterial lipid production regimes as indicated by principal component analysis (cf. Fig. 4). Fatty acids that co-eluted during chromatographic analysis (underlined; cf. Table S3) were quantified collectively.

Table 2. Bacterial lipid turnover times (years) in incubations of peat acrotelm and catotelm horizons. Uncertainty $( \pm)$ was based on error of concentration and $\delta \mathrm{D}$ measurements (cf. Sections 2.4 and 2.5). 


\section{Supplementary Text, Figures and Tables}

Text S1. Lipid concentrations and production rate estimates.

Figure S1. Example GC-FID chromatogram of FAME derivatives in oxic fen acrotelm incubated for one month. The first number of fatty acid abbreviations indicate the number of $C$ atoms. The numbers after the colon identify the number of double bonds whose position relative to the aliphatic end of the molecule is denoted by w. "Me" denotes the presence of a methyl group at the given carbon atom, and " $\mathrm{i}$ " (iso) and "ai" (anteiso) indicate methyl-branching at the aliphatic end by one or two $C$ atoms, respectively. Unknown methyl branching is indicated by "Me-br." Italics denote fatty acids for which assignments were based on retention time alone, as there was insufficient evidence after GC-MS to support unequivocal identification of FAME derivatives.

Figure S2. (A) Example GC-IRMS chromatogram ( ${ }^{1} \mathrm{H}$ signal) of brGDGT derivatives $1,2 \mathrm{a}$, and $2 c$ harvested from oxic fen acrotelm incubated for one month. (B-D) GC-MS identification and molecular cleavage patterns of brGDGT derivatives $1,2 a$, and $2 c$ corresponding to peaks in $(A)$.

Figure S3. $\delta D$ values of individual fatty acids in the poisoned incubations of bog $(x)$ and fen (o) acrotelm. Expanded axes for the values plotting in the shaded region are provided in the insert.

Figure S4. Production rates of fatty acids normalized to total fatty acid production in each incubation.

Figure S5. (A and B) Weighted average of D incorporation into FAMEs (red), brGDGT-CLs (blue), and brGDGT-IPLs (teal) in bog and fen catotelm (squares) as well as acrotelm incubated under initially oxic (circles) or anoxic (triangles) conditions, or poisoned $(x)$. Panels (C) and (D) show the $D$ incorporation into fatty acids relative to $t_{0}$ in bog and fen incubations, respectively. In the case of co-elution (cf. Table S3), the integrated $\delta \mathrm{D}$ value is labeled by only one of the co-eluting fatty acids.

Table S1. Estimated time for $\mathrm{O}_{2}$ depletion in aerobic incubations of acrotelm samples.

Table S2. Molecular mass, branching, and cyclopentane ring characteristics of brGDGTs.

Table S3. Concentrations of brGDGTs and fatty acids ( $\mu \mathrm{g} \mathrm{g}^{-1}$ humid peat) in peat samples at $\mathrm{t}_{0}$ and after one $\left(\mathrm{t}_{1}\right)$ or two months $\left(\mathrm{t}_{2}\right)$ of incubation. $n . d$., not detected.

Table S4. $\delta D$ values of lipid biomarkers in natural peat $\left(t_{0}\right)$ and after one $\left(t_{1}\right)$ or two months $\left(\mathrm{t}_{2}\right)$ of incubation. n.d., not detected

Table S5. $\delta^{13} \mathrm{C}$ values of lipid biomarkers in natural peat $\left(\mathrm{t}_{0}\right)$ and after one $\left(\mathrm{t}_{1}\right)$ or two months $\left(\mathrm{t}_{2}\right)$ of incubation. n.d., not detected 
Table S6. Constraining measurement error on lipid biomarkers labeled with deuterium. PMI = pentamethyisocane; unsPMI = unsaturated pentamethylisocane. 
Figure 1.

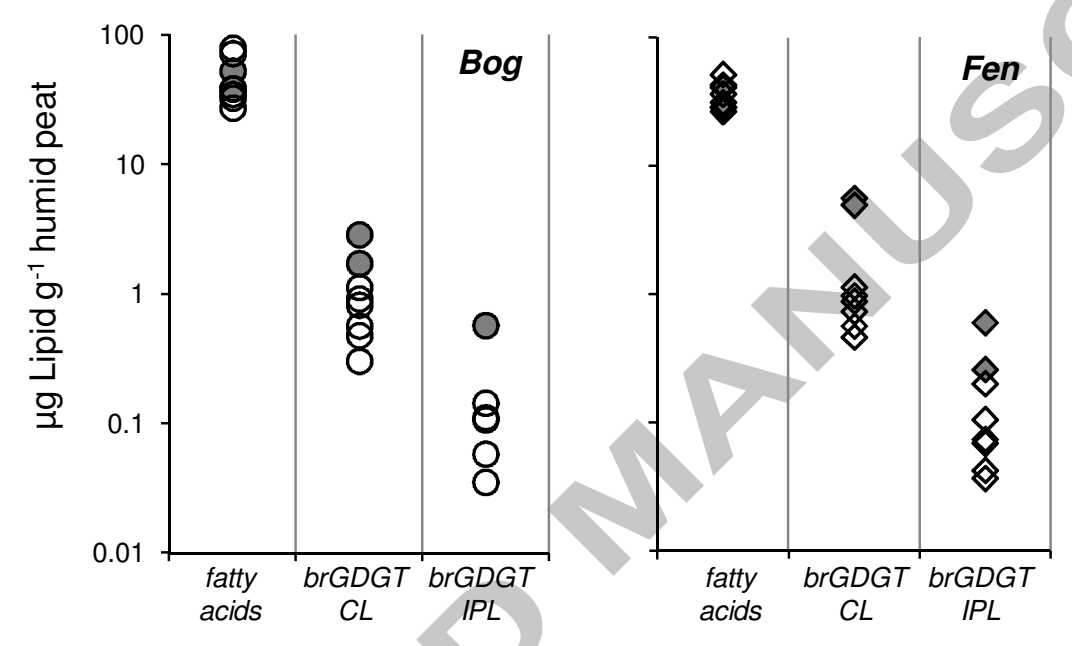


Figure 2.

Fractional Abundance

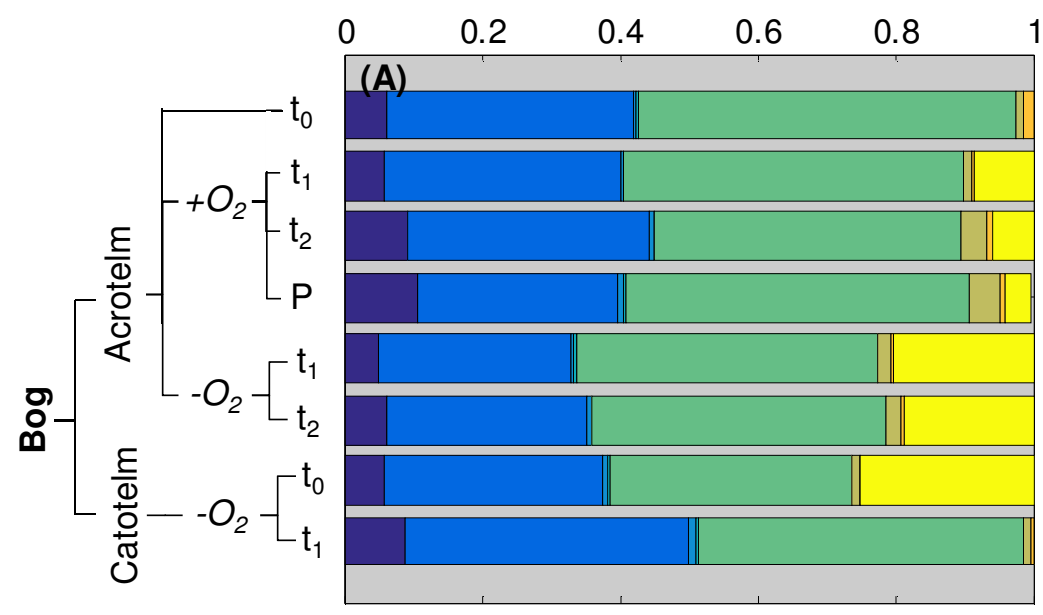

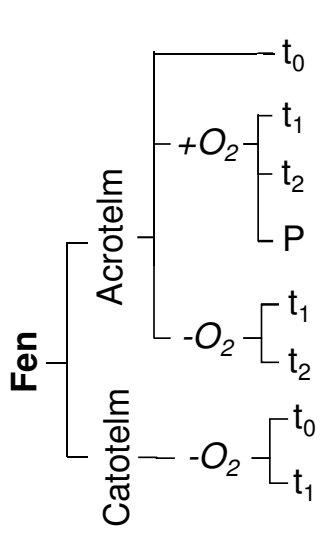

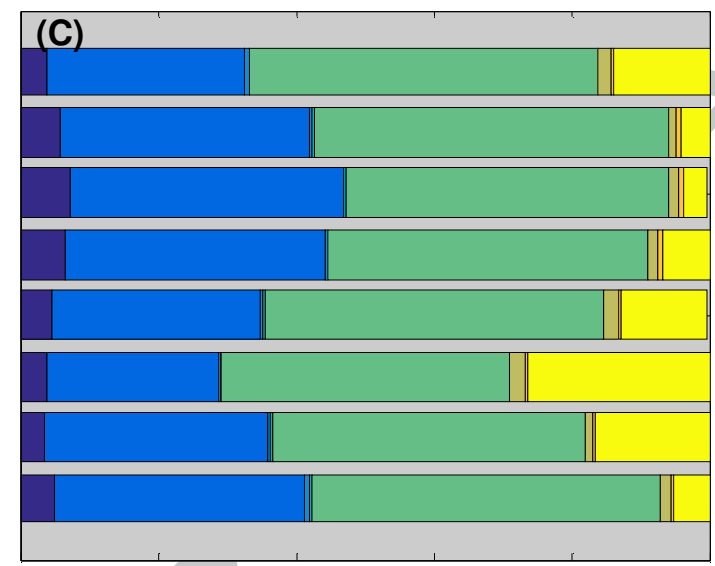

\begin{tabular}{|c|c|}
\hline 1050 & 1022 \\
\hline 1036 & 1020 \\
\hline | 1034 & 1018 \\
\hline 1032 & brGDGT-IPL \\
\hline
\end{tabular}

Production Rate $\left(\mathrm{ng} \mathrm{cm}^{-3} \mathrm{y}^{-1}\right)$
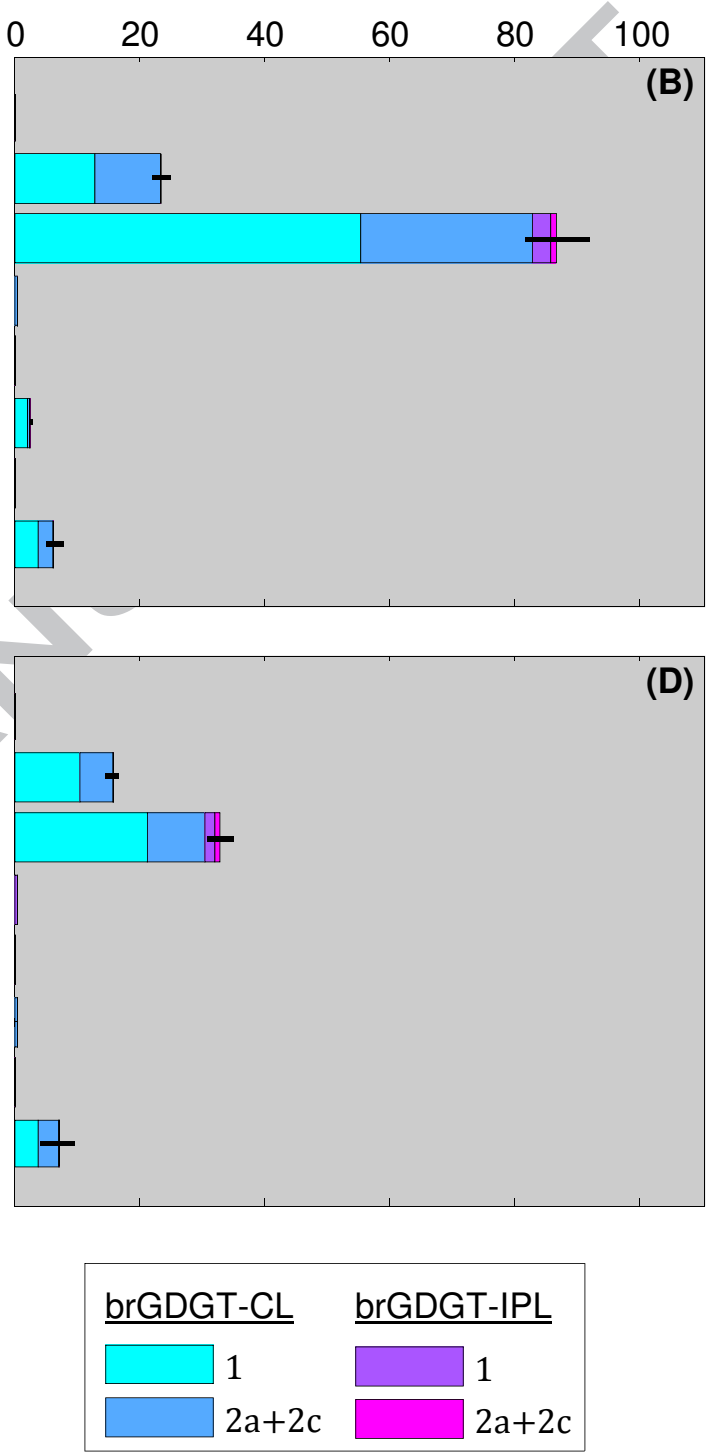
Figure 3.
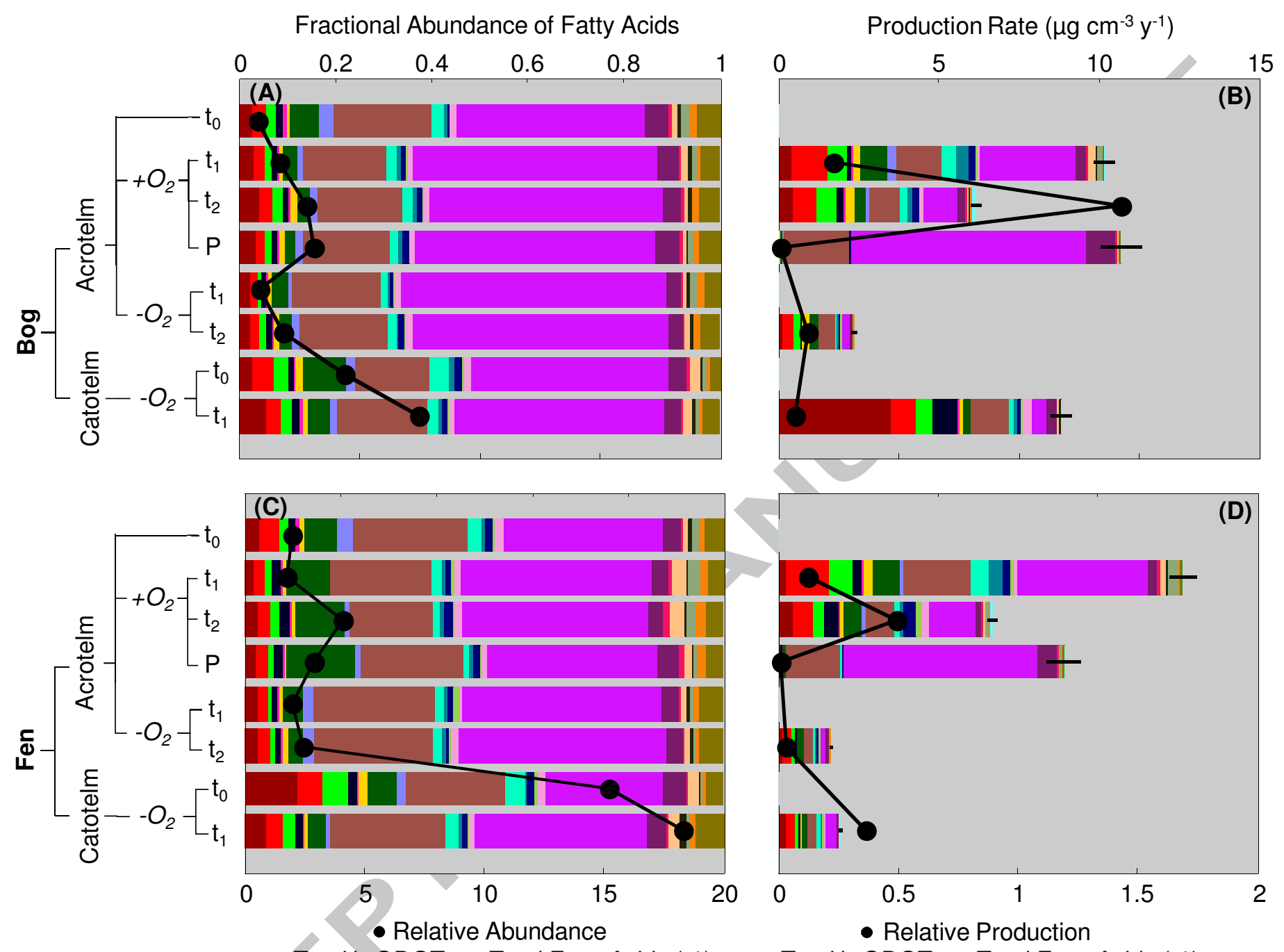

(D)

Total brGDGTs to Total Fatty Acids (\%)

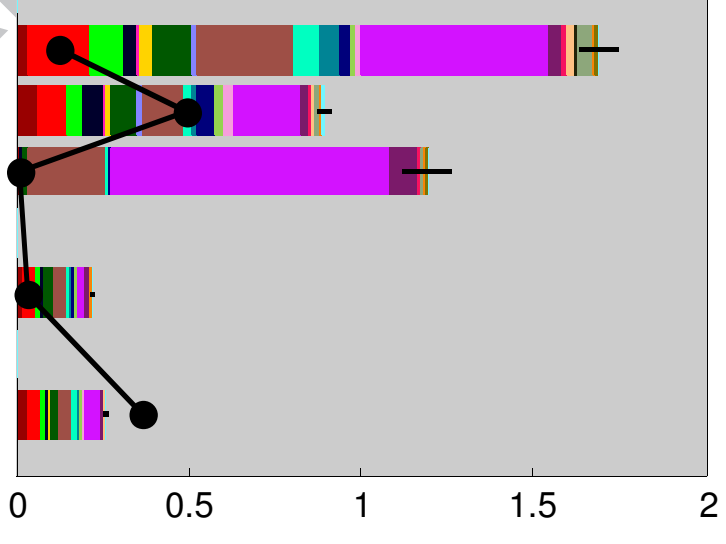

- Relative Production

Total brGDGTs to Total Fatty Acids (\%)
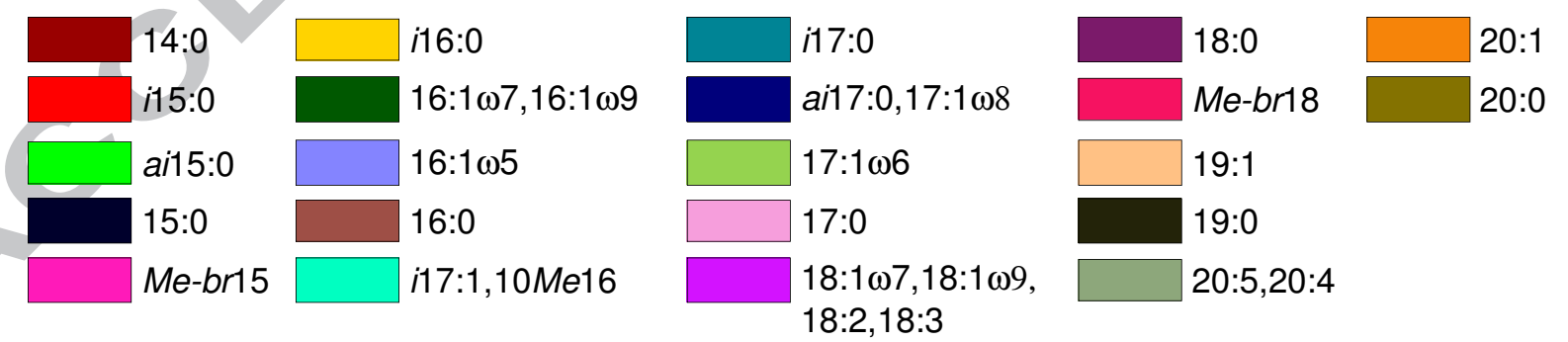
Figure 4.
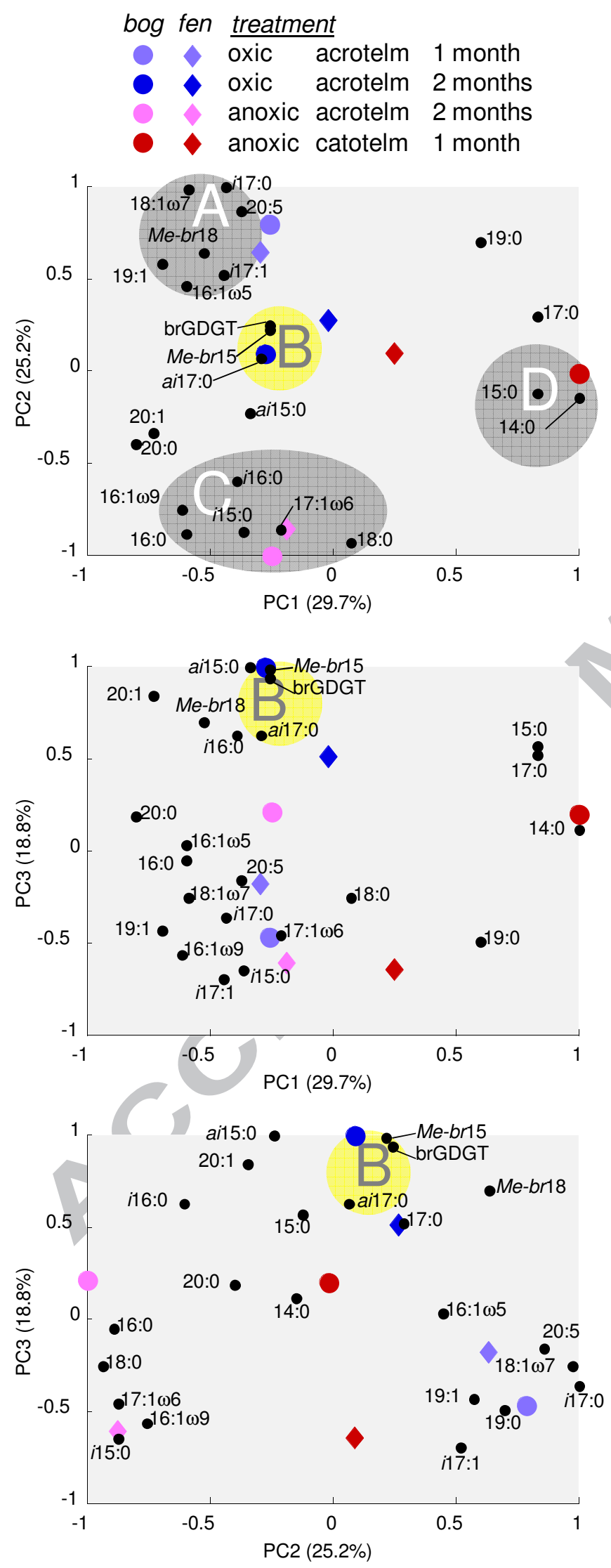
Figure 5.

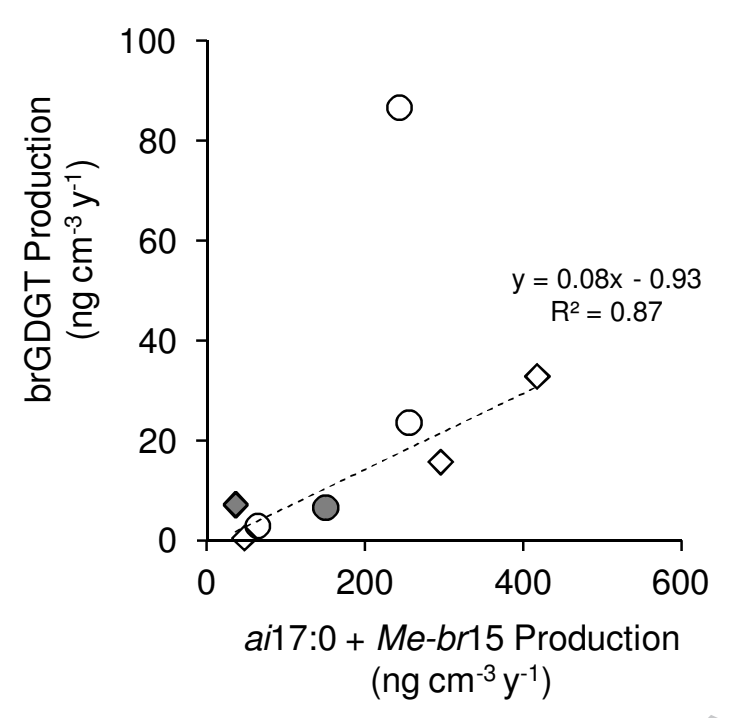


Table 1. Bacterial lipid production regimes as indicated by principal component analysis (cf. Fig. 4). Fatty acids that co-eluted during chromatographic analysis (underlined; cf. Table S3) were quantified collectively.

\begin{tabular}{|c|c|c|c|c|}
\hline $\begin{array}{c}\text { PCA } \\
\text { Cluster }\end{array}$ & Horizon & $\begin{array}{l}\text { Initial } \\
\text { Conditions }\end{array}$ & $\begin{array}{l}\text { Time point } \\
\text { (months) }\end{array}$ & Bacterial Lipid Production Signature \\
\hline A & $\begin{array}{l}\text { Bog \& Fen } \\
\text { Acrotelm }\end{array}$ & oxic & 1 & $\begin{array}{c}16: 1 \omega 5, i 17: 1, i 17: 0, M e 16: 0,18: 3,18: 2, \\
\quad \underline{18: 1 \omega 9,18: 1 \omega 7}, 19: 1, \underline{20: 5,20: 4}\end{array}$ \\
\hline B & $\begin{array}{l}\text { Bog \& Fen } \\
\text { Acrotelm }\end{array}$ & oxic & 2 & brGDGT, $M e-b r 15: 0, a i 17: 0,17: 1 \omega 8$ \\
\hline $\mathrm{C}$ & $\begin{array}{l}\text { Bog \& Fen } \\
\text { Acrotelm }\end{array}$ & anoxic & 2 & $i 15: 0,16: 1 \omega 9,16: 1 \omega 7,16: 0,17: 1 \omega 6,18: 0$ \\
\hline $\mathrm{D}$ & Bog Catotelm & anoxic & 1 & $14: 0,15: 0$ \\
\hline
\end{tabular}


Table 2. Bacterial lipid turnover times (years) in incubations of peat acrotelm and catotelm horizons. Uncertainty ( \pm ) was based on error of concentration and $\delta D$ measurements (cf. Sections 2.4 and 2.5).

\begin{tabular}{ccccccc}
\hline Sample & Horizon & $\begin{array}{c}\text { Initial } \\
\text { Conditions }\end{array}$ & $\begin{array}{c}\text { Time point } \\
\text { (months) }\end{array}$ & Fatty Acids & $\begin{array}{c}\text { brGDGT- } \\
\text { CL }\end{array}$ & $\begin{array}{c}\text { brGDGT- } \\
\text { IPL }\end{array}$ \\
\hline \multirow{3}{*}{ Bog } & acrotelm & Oxic & 1 & $5.2 \pm 1.0$ & $35 \pm 4$ & - \\
& acrotelm & Oxic & 2 & $4.2 \pm 0.8$ & $8 \pm 1$ & $11 \pm 2$ \\
& acrotelm & Anoxic & 2 & $10 \pm 2$ & $123 \pm 14$ & - \\
& catotelm & Anoxic & 1 & $2.6 \pm 0.6$ & $322 \pm 80$ & - \\
\hline \multirow{3}{*}{ Fen } & acrotelm & Oxic & 1 & $3.0 \pm 0.6$ & $41 \pm 4$ & - \\
& acrotelm & Oxic & 2 & $3.2 \pm 0.6$ & $27 \pm 3$ & $14 \pm 2$ \\
& acrotelm & Anoxic & 2 & $12 \pm 2$ & $742 \pm 217$ & - \\
& catotelm & Anoxic & 1 & $11 \pm 2$ & $514 \pm 197$ & - \\
\hline
\end{tabular}

